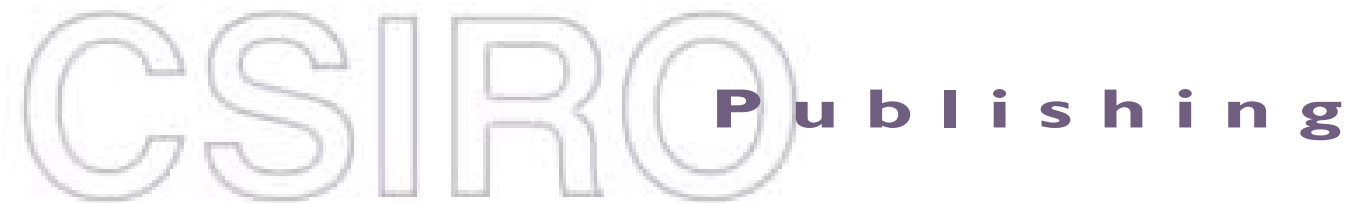

\section{Publications of the Astronomical Society of Australia}

Volume 19, 2002

(C) Astronomical Society of Australia 2002

An international journal of astronomy and astrophysics

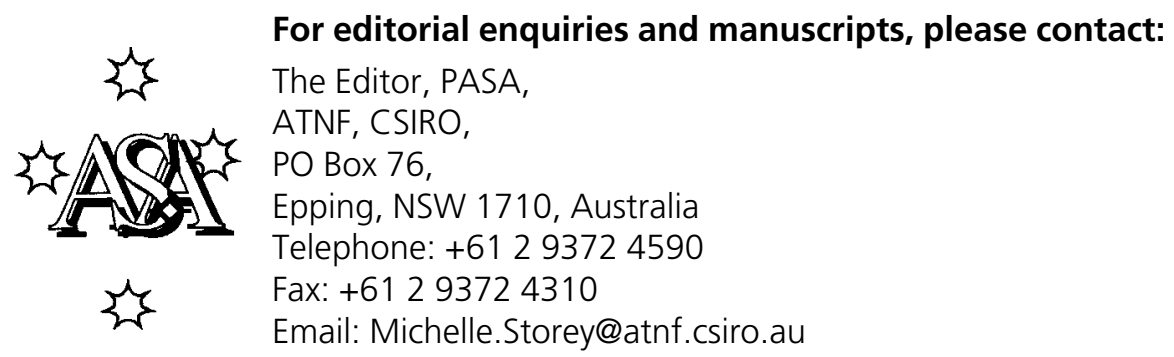

For general enquiries and subscriptions, please contact: CSIRO Publishing PO Box 1139 (150 Oxford St)

Collingwood, Vic. 3066, Australia

Telephone: +6139662 7666

Fax: +61 396627555

Email: publishing.pasa@csiro.au

C S I RO

PUBLISHING Published by CSIRO Publishing

for the Astronomical Society of Australia

www.publish.csiro.au/journals/pasa 


\title{
The Internal Extinction Curve of NGC 6302 and its Extraordinary Spectrum
}

\author{
Brent Groves $^{1}$, Michael A. Dopita ${ }^{1}$, Robert E. Williams ${ }^{2}$ and Chon-Trung Hua ${ }^{3}$ \\ ${ }^{1}$ Research School of Astronomy and Astrophysics, Australian National University, \\ Cotter Rd, Weston, ACT 2611, Australia \\ bgroves@mso.anu.edu.au, Michael.Dopita@anu.edu.au \\ ${ }^{2}$ Space Telescope Science Institute, 3700 San Martin Drive, Baltimore, MD, 21218, USA \\ wms@stsci.edu \\ ${ }^{3}$ Laboratorie d'Astronomie Spatiale, Marseille, France \\ Trung.Hua@astrsp-mrs.fr \\ Received 2002 March 26, accepted 2002 May 17
}

\begin{abstract}
In this paper we present a new method for obtaining the optical wavelength-dependent reddening function of planetary nebulae (PN), using the nebular and stellar continuum. The data used was a spectrum of NGC 6302 obtained using the Double Beam Spectrograph on the $2.3 \mathrm{~m}$ telescope at Siding Springs Observatory over three nights. This resulted in a spectrum covering a wavelength range $3300-8600 \AA$ with a large dynamical range and a mean signal to noise of $>10^{2} \AA^{-1}$ in the nebular continuum. With such a high S/N the continuum can be accurately compared with a theoretical model of nebular plus stellar continuum. The nebular electron temperature and density used in the model are determined using ratios of prominent emission lines. The reddening function can then be obtained from the ratio of the theoretical and the observed continuum. In the case of NGC 6302, it is known that much of the reddening arises from dust within or around the nebula, so that any differences between the measured reddening law and the 'standard' interstellar reddening law will reflect differences in the nebular grain size distribution or composition. We find that for NGC 6302, the visible to IR extinction law is indistinguishable from 'standard' interstellar reddening, but that the UV extinction curve is much steeper than normal, suggesting that more small dust grains had been ejected into the nebula by the PN central star. We have detected the continuum from the central star and determined its Zanstra temperature to be of order 150,000 K. Finally, using the extinction law that we have determined, we present a complete dereddened line list of nearly 600 emission lines, and report on the detection of the $\mathrm{He}(2-10)$ and $\mathrm{He}(2-8)$ Raman features at $\lambda 4331 \AA$ and $\lambda 4852 \AA$, and the detection of Raman scattered O vI features at $\lambda 6830 \AA$ and $\lambda 7087 \AA$. We believe this to be the first detection of this process in a $\mathrm{PN}$.
\end{abstract}

Keywords: planetary nebulae: individual (NGC 6302) — dust, extinction

\section{Introduction}

Because interstellar dust grains are very small, typically less than a micron in diameter, their absorption and scattering properties are not only composition-dependent but also wavelength-dependent. Blue and UV light is usually preferentially scattered compared to that of longer wavelengths. Dust grains cannot only absorb and scatter light from objects, they can also re-emit in the thermal infrared, polarise light through grain alignment mechanisms, or be accelerated, heated, and photoelectrically charged by the electromagnetic radiation which impinges upon them.

All of these processes are known to occur in the planetary nebula (PN) environment. In particular, during the asymptotic giant branch (AGB) phase of evolution, mass loss releases material into the circumstellar environment which has undergone partial nuclear processing in the central star. Since this environment is fairly cool, dust may be formed by direct condensation out of the gaseous phase whenever the kinetic temperature of the gas falls below a critical value which allows solids to form. In this case, we have a gas which is slowly cooling from higher temperatures and in which the pressure and supersaturation are high enough to allow both nucleation and grain growth.
However, it is unlikely that there exists a state of thermodynamic equilibrium in the dust-forming gas, and shock heating and cooling are often both important. Therefore, a complex and detailed time-dependent description of the chemical reactions, usually referred to as a kinetic model, is needed to describe this situation.

Because of the physics of the condensation process, and the interaction between the grains formed in the flow and the radiation field of the star, there is a complex relationship between the nature of the grains, their size distribution, and the terminal velocity of the dusty outflow. Kozasa \& Sogawa (1997) showed that the grain size increases as the mass-loss rate increases, since the size of the grain produced by condensation depends upon the gas density in the wind where a strong supersaturation exists in the gaseous phase, and upon the period during which the condensation timescale is much shorter than the dynamical expansion timescale. On the other hand, radiation pressure acting upon the grains accelerates the stellar mass-loss flow (thereby arresting the condensation process). This has been seen observationally by Loup et al. (1993) and explained theoretically by Habing, Tignon, \& Tielens (1994). The expansion velocities of the 
carbon rich objects are larger than those of the oxygen rich AGB stars, and radiation pressure induced expansion of the atmosphere may limit the size of the typical carbon-bearing grain to $\sim 50 \AA$, similar to that which is needed to explain the $2175 \AA$ bump in the interstellar extinction curve. During the PN phase of evolution, we expect the grain size distribution to be further modified by radiative destruction processes (photoevaporation and Coulomb destruction by excessive photoelectric charging) and by mechanical processes (grain coagulation and shattering).

Taking all of these considerations into account, it is clear that we should expect that the dust formed in the gas ejected during the AGB phase, and later observed in the $\mathrm{PN}$ phase, would be quite unlike, like that seen in the interstellar medium as a whole. It is therefore of great interest to either observe this dust directly through IR observations, or else through the extinction produced by it in the optical and UV.

As far as direct observations are concerned, enormous progress has recently been made using the ISO satellite to obtain spectroscopy of the far-IR emission features characteristic of different grain materials (Waters et al. 1996). The bright southern PN NGC 6302 is an ideal object for such studies, as it is known to have within it a dense circumstellar torus containing the bulk of the dust mass (Lester \& Dinerstein 1984), and within this a dense ring of ionised gas, inclined at about $45^{\circ}$ to the plane of the sky (Rodriguez et al. 1985). Recently, Kemper et al. (2002) have reported the detection of features in the farIR spectrum of this object which may be ascribed to the silicates amorphous olivine, forsterite, clino-enstatite, and diopside. In addition features due to water ice and metallic iron are seen. Remarkably, the carbonates calcite and dolomite were also detected.

At optical wavelengths, the lack of strong spectral features renders such exquisite mineralogy impossible. However, because dust grain dimensions are often comparable to or smaller than the wavelength of light, the dust extinction curve can in principle be used as a powerful constraint on the grain size distribution in the nebula.

For PN we usually characterise the reddening by a single 'reddening constant' $c$, and then assume that the absorption through the optical wavelength region can be fitted by a 'standard' Whitford reddening law (Whitford 1958). This curve, $f(\lambda)$, can then be used to deredden the observed emission line fluxes. The relationship between the corrected flux, $F_{\mathrm{c}}$, and that observed, $F_{\mathrm{o}}$, is:

$$
F_{\mathrm{c}}=F_{\mathrm{o}} \times 10^{c f(\lambda)}
$$

The reddening constant is usually determined from a comparison of the ratio of the intensities of the Balmer lines, since this 'Balmer decrement' is only slightly dependent upon the temperature and density of the nebula, and the theoretical values are well determined. Alternatively, we can compare the radio continuum flux density and the $\mathrm{H} \beta$ flux. The radio emission is basically free from interstellar reddening and the ratio between the radio continuum flux and the $\mathrm{H} \beta$ flux is determined only by the electron temperature and the relative helium abundance. A third technique is to measure the ratio of two emission lines which share a common upper energy level, such as $\mathrm{H} \beta$ and $\operatorname{Br} \gamma$ (Ashley 1990).

All of these methods have their problems. In the first case, the reddening is determined at only a few discrete wavelengths, and over a restricted wavelength range. In the other two cases, we may be seeing regions of ionised gas in the radio or at IR wavelengths which are entirely dust-obscured in the optical, and therefore we can neither correctly evaluate the effective total obscuration nor the differential extinction at different optical wavelengths in the nebular gas.

The motivation behind the work described in this paper is to obtain an intrinsic reddening function which does not depend on the Whitford curve, which is continuous in its wavelength coverage, and which can be used to place constraints on the grain size distribution in a planetary nebula.

To do this, we have obtained very high signal to noise observations of NGC 6302 covering the wavelength range 3300-8600 A, allowing observations of both Paschen and Balmer lines, and of both the Balmer and the Paschen discontinuities of hydrogen. We have then compared the observed continuum spectral energy distribution to a theoretical (nebular + stellar) spectral energy template to derive the reddening function. As far as we are aware, this represents the first practical application of this novel technique in the literature.

\section{Observations and Reduction}

NGC 6302 is a very bright, nearby Type I planetary nebula which displays a bipolar, filamentary structure. The central star of the nebula is believed to be very hot, with a temperature possibly as great as 430,000 K (Ashley \& Hyland 1988). However, the central star has never been identified either owing to heavy obscuration in the central parts of the nebula, or else owing to its extreme temperature.

To observe NGC 6302 we used the double beam spectrograph (DBS) (Rodgers, Conroy, \& Bloxham 1988) with its EEV CCD detectors on the $2.3 \mathrm{~m}$ telescope at Siding Springs Observatory. A $1200 \mathrm{l} / \mathrm{mm}$ grating was used in both the red and the blue arms giving a wavelength coverage of just over $1000 \AA$. We observed NGC 6302 over three photometric nights (6-8 July 1999) in 6 independent wavelength ranges, corresponding to 3 grating settings per arm. These settings, given below, were chosen to allow a slight overlap between each spectrum, and to avoid placing strong emission lines in the overlap region:

$$
\begin{array}{llll}
1 & 3300-4300(\mathrm{~B}) & 5800-6800(\mathrm{R}) & \text { Dichroic \#1 } \\
2 & 4200-5200(\mathrm{~B}) & 6700-7700(\mathrm{R}) & \text { Dichroic \#5 } \\
3 & 5100-6100(\mathrm{~B}) & 7600-8600(\mathrm{R}) & \text { Dichroic \#5 }
\end{array}
$$

Dichroic filter \#1 is the only one with satisfactory performance in the UV below the Balmer discontinuity, but for the second and third grating setups, Dichroic \#5 was 


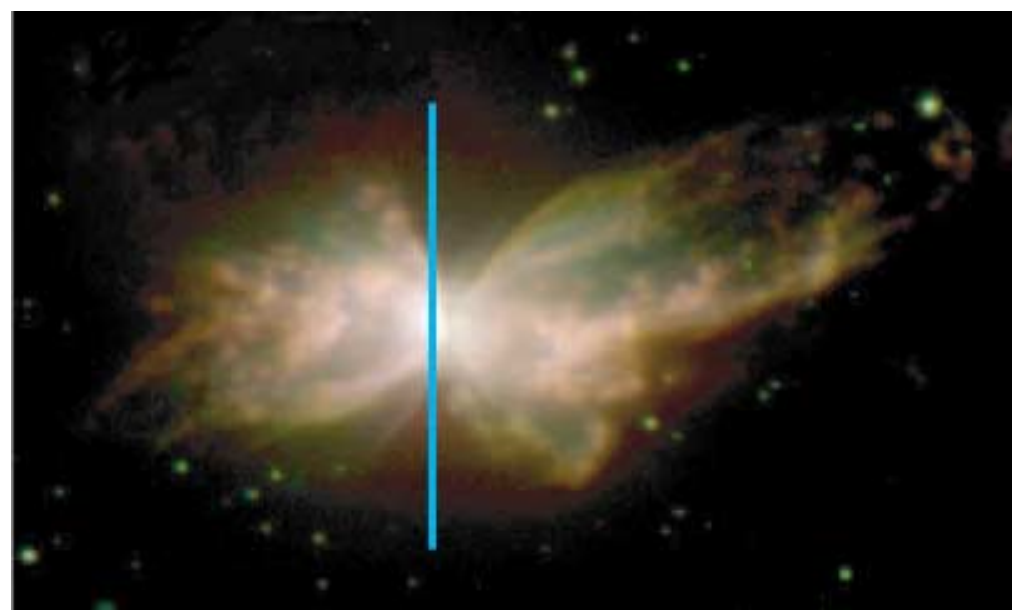

Figure 1 The planetary nebula NGC 6302 (Hua, Dopita, \& Martinis 1997). The placement of the $2.3 \mathrm{~m}$ slit on the nebula is indicated by the blue line.

used, since this gives smoother transmission characteristics in the red.

In order to obtain spectra of great dynamical range, we had to make a series of exposures of different lengths to ensure that we had good relative photometry for the bright emission lines, such as the $[\mathrm{O}$ III] $\lambda 5007$ line, which were saturated on the detector in the longer exposures. Three independent frames were taken for each exposure time to eliminate cosmic ray events and to reduce the noise in the final spectrum. The full set of exposures for each pair of grating settings was: (1) 20, 60, 200, 500, and $1500 \mathrm{~s}$; (2) $20,60,180,600$, and $1500 \mathrm{~s}$; (3) 500, and $1500 \mathrm{~s}$. Only two exposures were required at the third setting because of the lack of strong emission lines in these two regions. Each spectrum was 1850 pixels in length and covered 200 spatial pixels, each corresponding to 0.91 arcsec on the sky.

The slit width was chosen to be 2 arcsec. This optimises the throughput without appreciable degradation of the spectral resolution. The slit was placed on the brightest optical region of NGC 6302 as shown in Figure 1. This image was obtained using the $2.3 \mathrm{~m}$ imager, and is a colour composite of three observations through narrowband filters isolating blue ([O III $] \lambda 5007)$, green $(\mathrm{H} \alpha)$, and red ([N II] $\lambda 6584)$.

For wavelength calibration a neon-argon arc lamp was used, and for flux calibration the standard stars EG131 and Feige110 (Bessell 1999) were observed. The star EG131 is particularly useful, because it lies not too far away on the sky from NGC 6302, and can therefore be used as an atmospheric standard as well. The flat field was generated by observing, through the spectrograph, the diffuse reflection of a white-painted region of the shutter of the dome of an array of quartz-iodide lamps placed around the upper secondary support ring structure of the telescope.

The reduction of the data was done using the IRAF package. The reduction procedure was fairly complex, because of the number of observations, and the large dynamical range targeted for the final spectrum.

For each frame, the bias observed for that particular night was removed. However, as the telescope tracks, the spectrograph which is mounted at the Nasmyth A focus rotates, and consequently there is a temperature shift in the pre-amplification and CCD control electronics rack which is mounted on the spectrograph. This results in a systematic bias drift, which has to be removed in each frame by reference to the bias strip using the tasks IMSTAT and IMARITH. The spectrograph rotation also produces flexure which results in a small shift of the spectrum. To eliminate this, each set of three spectra was aligned relative to the observation that was nearest the arc observation using the IRAF task IMALIGN and then combined using the IMCOMBINE option with the CCDREJECT option to remove cosmic ray events.

Flat fields were prepared by dividing each flat field observation by a low order spline surface fit to the flat field to remove (to first order) the gross effects due to the spectral energy distribution of the quartz iodide lamps. At the UV end of the spectrum, around 3500-3300 $\AA$, the accuracy of the flat field is limited by the photon statistics in the lamp. The flat fielding removes not only the pointlike defects due to dust and blemishes in the CCD, but also the oscillations in the transmission of the dichroic beamsplitters, which are particularly noticeable in the red arm, close to the cutoff wavelength.

Following this, one dimensional spectra were extracted from a $\sim 6$ arcsec length of slit centred on the eastern hot-spot. From this point, the data reduction follows the standard procedures described in the IRAF handbooks. The standard stars are also used as atmospheric standards to correct, as best as possible, for the $\mathrm{OH}$ atmospheric molecular band absorptions in the red.

After reduction, there remain a number of minor but significant problems in the data. First, the 4200-5200 observation suffers from grossly out of focus ghost images (produced in the camera) of the very bright [O III] $\lambda 4959, \lambda 5007 \AA$ lines. These cannot be fully removed from the data, and corrupt the continuum measurements in the $\sim 4300-4600 \AA$ wavelength range. In addition, the [O III] lines themselves were so intense that in the long exposures, not only were the CCD columns containing 

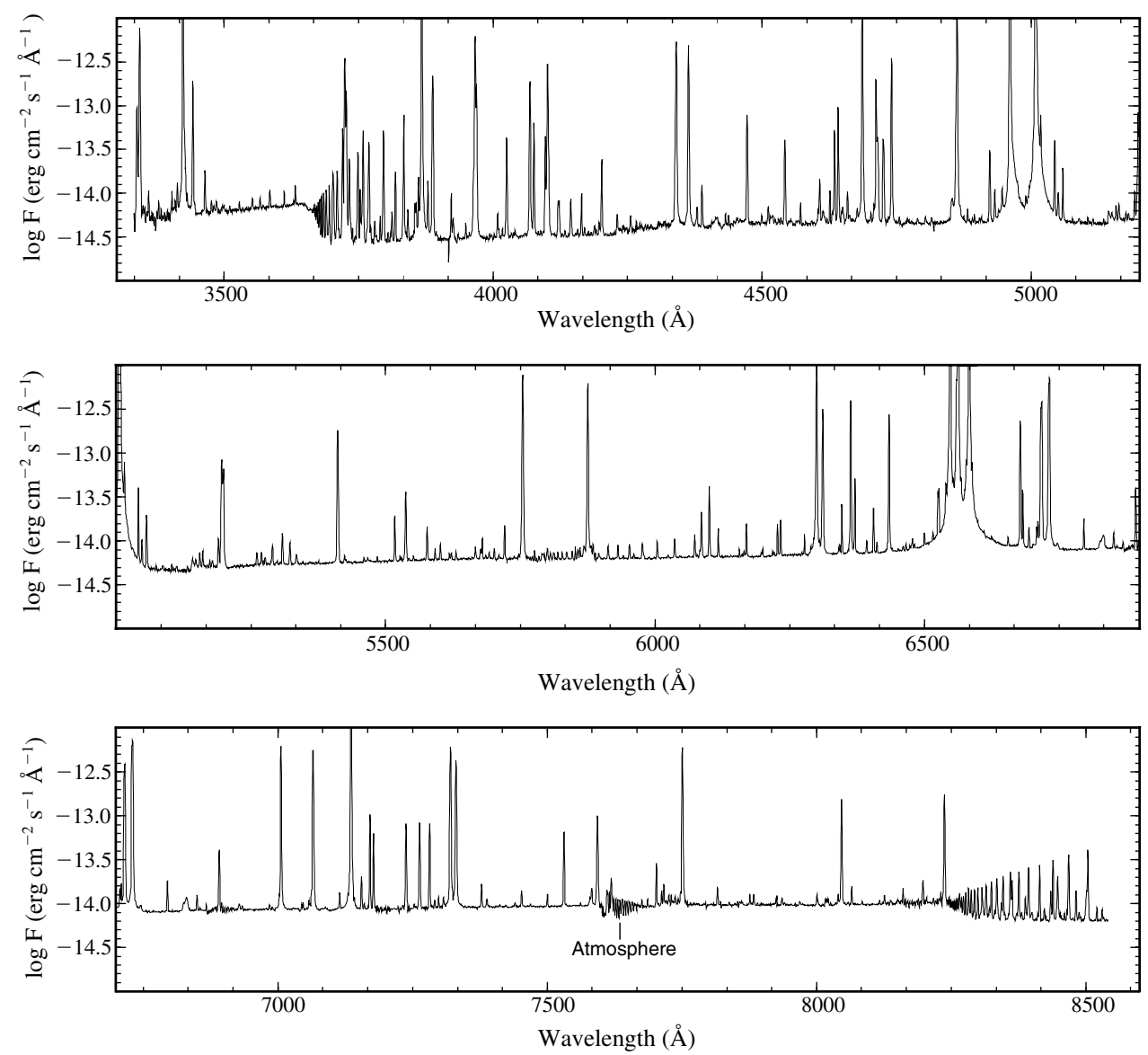

Figure 2 The spectrum of NGC 6302 covering a wavelength range of 3300-8600 $\AA$ and a very large dynamic range. Also visible in the spectrum is the nebular continuum, with a typical S/N greater than $10^{2} \AA^{-1}$. A full line list from this spectrum is given in Table 3.

these lines completely saturated, there was also appreciable bleeding in the line direction as well, up to the boundary of the chip near $5300 \AA$. An attempt has been made to correct for this effect, but the continuum fluxes measured in this spectral range remain less reliable.

Second, the absolute fluxes measured in the individual spectra differed from night to night, as judged from the overlap regions. This is probably mainly due to small errors in the re-positioning of the slit, despite the fact that the same centring and guide star offset figures were used for all three nights. Since the first night's observations cover $\mathrm{H} \alpha$ in the red, $\mathrm{H} \delta$ and beyond, down to the Balmer continuum in the blue, the remaining spectra were normalised by a fixed multiplicative factor to best remove any discontinuities in the overlap region.

Lastly, spectrograph drifts due to differential flexure problems during the long exposures provide a larger uncertainty in the absolute wavelength calibration than is desirable, with errors ranging up to $0.6 \AA$. However, the absolute wavelength scale is generally very accurately determined, with an error as small as $\sim 0.03 \AA$. However, in some cases, the lack of arc lines in the overlap region sometimes means that the systematic wavelength error in these regions may increase to up to $0.6 \AA$. Thus, the absolute wavelengths of individual spectral features should only be measured relative to nearby known hydrogen or helium lines, observed at the same time as the feature of interest.

In the long exposure ( $4500 \mathrm{~s}$ integration time) combined spectrum, several of the bright lines were saturated on the CCD, sometimes quite grossly. The regions of saturation were determined, and the flux in these overexposed regions was replaced by that measured in a shorter exposure in which these lines were not saturated. This gives a full spectrum which has a large wavelength range, high resolution, large $\mathrm{S} / \mathrm{N}$ ratio, and a very large dynamic range, shown in Figure 2. Typically the mean signal to noise in the nebular continuum is $>10^{2} \AA^{-1}$. Hundreds of emission lines are visible. The identifications ascribed to these, and their relative intensities, are discussed below. Note the prominent Balmer and Paschen discontinuities in the nebular continuum.

\section{The Theoretical Nebular Continuum}

The continuum emission from a planetary nebula comes from several processes. Given the temperature and density of the nebula and abundance of the emitting species, the full continuum emission from the nebula can be theoretically predicted. In the theoretical continuum emission calculated here the three main nebular emission processes 
were taken into consideration: free-free emission, freebound emission, and two-photon continuum. The two major elements, hydrogen and helium, were the only species considered as contributing to these processes. The theory of these processes, along with useful tables, is summarised by Dopita \& Sutherland (2002).

For the first two processes, a simplified fit to the theoretical continuum emission due to hydrogen and the two ionic states of helium has been calculated from Brown \& Mathews (1970), which is applicable over the range of temperatures liable to be encountered. We fit the peaks of emission coefficient near prominent discontinuities (such as the Balmer jump) with functions of the form

$$
\gamma_{\nu} \propto T^{\alpha}\left(1+\beta[\ln (T)]^{2}\right)
$$

with the constants $\alpha$ and $\beta$ and the constant of proportionality determined from the data for each peak.

Between discontinuities we fit the gradient of $\log \left(\gamma_{\nu}\right)$ vs $v$ with a power law:

$$
\text { gradient } \propto T^{\alpha}
$$

with the constant $\alpha$ and the constant of proportionality determined from the data for each wavelength region between peaks.

To these we add the theoretical emission from the twophoton process. The usual assumption, that there is a large optical depth for Ly $\alpha$, was adopted. Finally, the possibility that there is a continuum due to the central star should also be allowed for in making a fit to the observed nebular continuum. Here, we simply assume that since the central star is so hot, the spectrum can be fitted by the RayleighJeans approximation for a black body.

The nebular continuum is normalised to the emissivity of $\mathrm{H} \beta$ which can be obtained from Osterbrock (1989) or, equivalently, from the tables in the appendices of Dopita \& Sutherland (2002).

In order to fit this model continuum to the observed data, we need to observationally determine the parameters of nebular temperature, nebular density, and abundances by number of the $\mathrm{He}^{+}$and $\mathrm{He}^{++}$ions relative to the $\mathrm{H}^{+}$ ion. These can be obtained with sufficient accuracy from the normal nebular diagnostics, provided that an initial estimate of the reddening can be determined, as shown in the following section.

\section{Determination of Nebular Properties}

There are a number of density sensitive line ratios available in the spectrum. These include the usual [O II] $\lambda 3726 /$ $\lambda 3729$ and $\left[\mathrm{S}_{\mathrm{II}}\right] \lambda 6731 / \lambda 6717$ line ratios, as well as the [Ar IV] $\lambda 4740 / \lambda 4711$ and $[\mathrm{Cl}$ III] $\lambda 5537 / \lambda 5517$ line ratios which are not as frequently used because the lines are fainter, and their use requires spectra of higher signal to noise. Since all these line pairs are close in wavelength, we do not have to worry about reddening corrections. The densities have been obtained from these ratios using the Australian version of the MAPPINGS III code (Sutherland \& Dopita 1993). The derived densities are listed in Table 1.
Table 1. The measured electron density for NGC 6302 from several line ratios

\begin{tabular}{ll}
\hline Line ratio & Density $\left(10^{4} \mathrm{~cm}^{-3}\right)$ \\
\hline$[\mathrm{O}$ II $] \lambda 3726 / \lambda 3729$ & 0.5 \\
{$\left[\mathrm{~S} \mathrm{II}^{\mathrm{I}} \lambda 6731 / \lambda 6717\right.$} & 0.8 \\
{$[\mathrm{Ar}$ IV $] \lambda 4740 / \lambda 4711$} & 1.3 \\
{$[\mathrm{Cl}$ III $] \lambda 5537 / \lambda 5517$} & 2.0 \\
\hline
\end{tabular}

Table 2. The measured electron temperature for NGC 6302 from several line ratios

\begin{tabular}{ll}
\hline Line ratio & Temperature $\left(10^{4} \mathrm{~K}\right)$ \\
\hline$[\mathrm{O}$ III $] \lambda 4363 / \lambda 5007$ & 1.5 \\
{$[\mathrm{~N}$ II $] \lambda 5754 / \lambda 6583$} & 1.4 \\
{$\left[\mathrm{~S} \mathrm{II}^{\mathrm{I}}\right] 4076 / \lambda 6731$} & 1.2 \\
{$\left[\mathrm{O}_{\mathrm{I}}\right] \lambda 5577 / \lambda 6300$} & 1.0 \\
\hline
\end{tabular}

In order to estimate the nebular temperature from line ratios, we first need to adopt an estimate of reddening. This was done as a first approximation by measuring the Balmer decrement and comparing it with the theoretical decrement for an assumed electron temperature of $15,000 \mathrm{~K}$ (the choice of the electron temperature is not critical, since the Balmer decrement is only slightly dependent on the temperature). Individual line ratios can then be dereddened using the Whitford reddening curve (as tabulated by Kaler 1976). We find a reddening constant of $c=1.2$, in excellent agreement with that determined in the same way by Aller et al. (1981), who found $c=1.22$. It is interesting to note that these reddening values are lower than that obtained either from the $\mathrm{H} \beta$ to $\mathrm{Br} \gamma$ ratio $(c=2.44$, Ashley 1990), or the $\mathrm{H} \beta$ to radio continuum ratio $(c=2.1$, Milne \& Aller 1975; $c=2.1$, Ashley \& Hyland 1988). This is clear evidence that there exists a highly-obscured inner region in the nebula, visible only in the IR or at radio wavelengths.

The temperature sensitive lines used were [O III] $\lambda 4363 / \lambda 5007,[\mathrm{~N}$ II] $\lambda 5754 / \lambda 6583$, [S II] $\lambda 4076 / \lambda 6731$, and $\left[\mathrm{O}_{\mathrm{I}}\right] \lambda 5577 / \lambda 6300$. The temperatures obtained from these ratios are listed in Table 2. Since the emission is heavily weighted towards the high-excitation regions in our spectrum, we adopt a temperature of $T_{\mathrm{e}} \sim 1.5 \times 10^{4} \mathrm{~K}$ for the continuum model fitting described below.

To determine the helium ionic abundance, ratios between the Pickering (n-4) and (n-3) lines and the Balmer lines for He II and singlet lines such as $\lambda 6678$ and the Balmer lines for He I were used. We use the singlets for this purpose because, unlike the triplets, they are unaffected by optical depth and line transfer problems. The flux ratios were then used with the data from Osterbrock (1989) and from Dopita \& Sutherland (2002) to obtain the abundance of the $\mathrm{He}^{+}$and $\mathrm{He}^{++}$ions relative to $\mathrm{H}^{+}$.

The final parameters used in the calculation of the continuum are temperature $T_{\mathrm{e}} \sim 1.5 \times 10^{4} \mathrm{~K}$, electron density 
$n_{\mathrm{e}} \sim 1.0 \times 10^{4} \mathrm{~cm}^{-3}, \mathrm{He}^{+}$to $\mathrm{H}^{+}$abundance ratio $\sim 0.11$, and $\mathrm{He}^{++}$to $\mathrm{H}^{+}$abundance ratio $\sim 0.07$.

\section{The Reddening Curve for NGC 6302}

With the electron density, temperature, and helium ionic abundances estimated above, we first built a theoretical continuum of NGC 6302, as shown in Figure 3. This theoretical emission was then divided by the spectrum from NGC 6302 to provide an initial estimate of the reddening function. The result can be seen in Figure 4. The reddening function should be a smooth curve which is defined by the highest points in this function. The detailed structure is due to the individual emission lines. However, even ignoring these emission line features, large steps are evident at both the Balmer and Paschen jumps. These steps would not be removed even were we to assume a much larger electron temperature, and in any case the residual Balmer and Paschen jumps cannot both be simultaneously removed for any assumed value of the electron temperature.

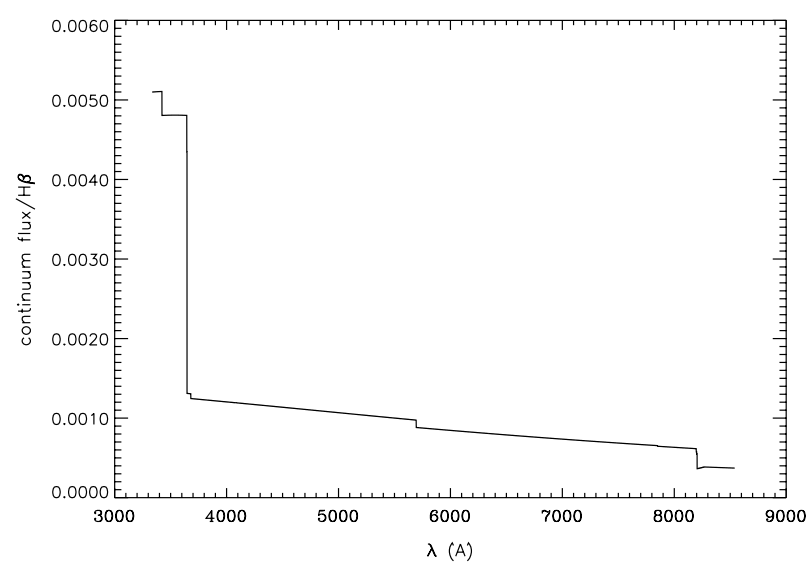

Figure 3 The theoretical continuum of NGC 6302 relative to $\mathrm{H} \beta$.

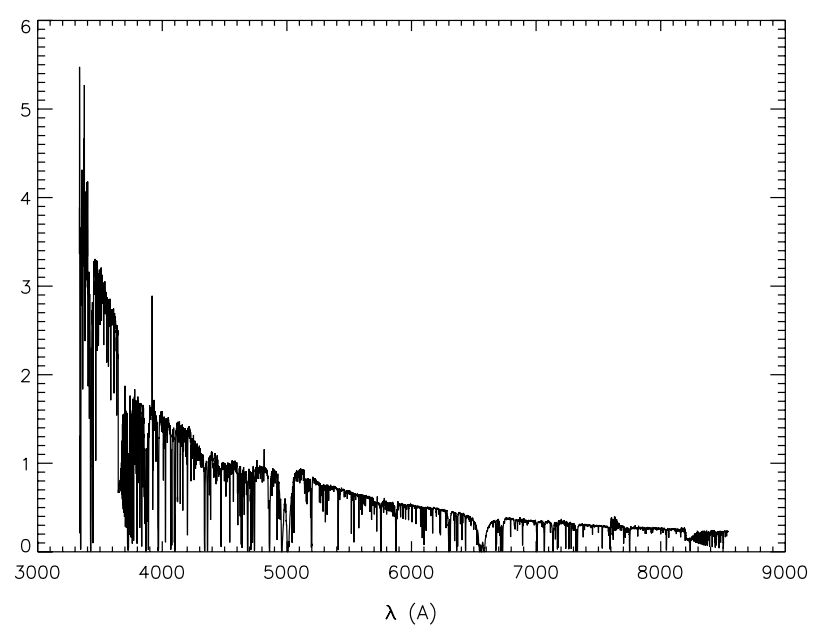

Figure 4 The theoretical continuum divided by the spectrum of NGC 6302 showing the need for the addition of a stellar continuum. The emission lines in the spectrum are responsible for the low values in this curve. The apparent features in the continuum between 4300 and $5200 \AA$ are artifacts of the saturation effects and ghost images of the [O III] lines described in Section 2 and should be ignored.
We are forced to conclude that these discrepancies are the result of the presence of a reflected and/or direct continuum from the hot central star as discussed in Section 3, producing a Rayleigh-Jeans tail of a black body spectrum in the visible $\left(F_{\lambda} \propto \lambda^{-4}\right)$.

The amount of stellar continuum which we need to add to match the observed Balmer jump determines the correct scaling factor of this black body component to add to the continuum template. The correctness of this scaling factor is evidenced by the fact that, when this is done, the other jumps such as the Paschen and He II jumps also match the observations. The resultant continuum model including the stellar contribution is shown in Figure 5 and the result of division of this by the observational data is shown in Figure 6.

This represents the first direct detection of the central star of NGC 6302 by any technique. However, it is more likely that this stellar flux represents scattered light rather than direct light, since the slit was displaced from the physical centre of the nebula by more than a slit width, the nebula is known to be extremely optically thick at its

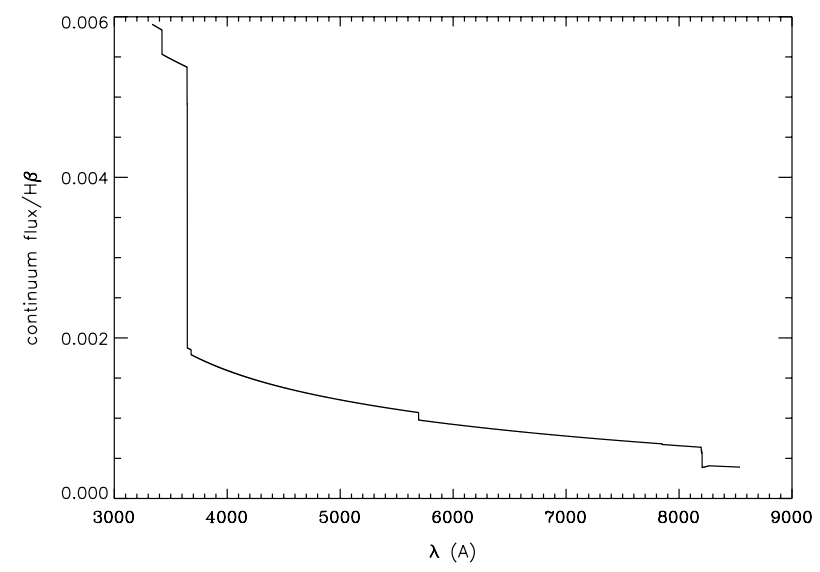

Figure 5 The theoretical continuum of NGC 6302, including the direct and reflected stellar continuum, relative to $\mathrm{H} \beta$.

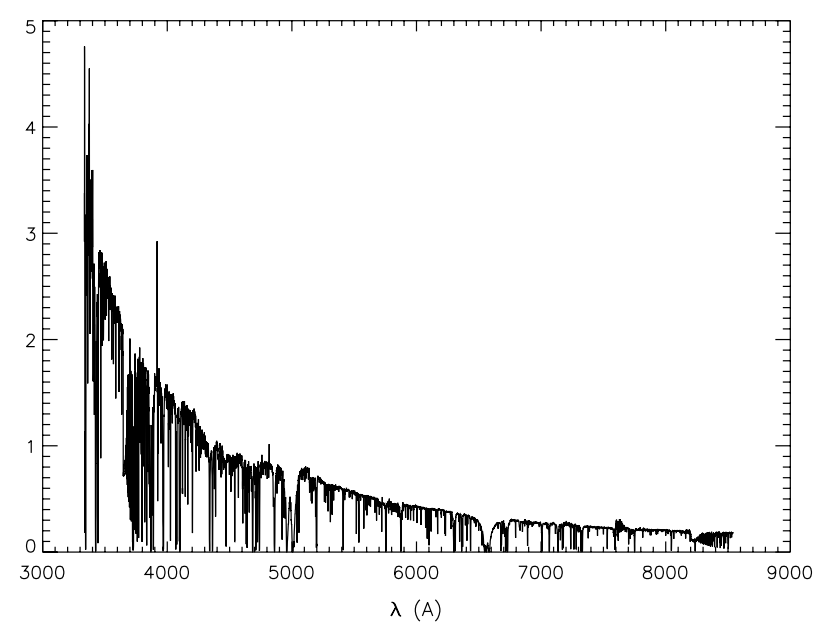

Figure 6 The full theoretical continuum, including stellar contribution, divided by the spectrum of NGC 6302, showing the reddening of the nebula. 
centre (Ashley 1990), and direct imaging searches for the central star have so far failed (Ashley 1988).

With this determination of the amount of stellar continuum in the spectrum we can now measure the Zanstra temperature of the central star, assuming that the stellar continuum is seen directly, rather than being scattered into the line of sight by the dusty torus, and that the central star lies fully within the slit.

At $\lambda 4681$, we find that the stellar continuum is $1.79 \times 10^{-4}$ that of $\mathrm{H} \beta$. This gives a flux at $\lambda 4681$ for the central star of $F_{*}=6.83 \times 10^{-16} \mathrm{erg} \mathrm{cm}^{-2}\left(\mathrm{~mW} \mathrm{~m}^{-2}\right)$. The global $\mathrm{H} \beta$ flux for NGC 6302 is $\log F_{\mathrm{H} \beta}=-10.55$ (Perek 1971), giving an $\mathrm{H} \beta$ to stellar flux ratio of $\log$ $F_{\mathrm{H} \beta} / F_{*}=4.61$. Using the figures provided in Pottasch (1984) this leads to an estimate for the Zanstra temperature of $T_{\mathrm{z}} \sim 1.5 \times 10^{5} \mathrm{~K}$.

This temperature is well below the $430,000 \mathrm{~K}$ determined by Ashley \& Hyland (1988) using high excitation silicon lines. If we are not seeing the central star directly, but through scattered light, this discrepancy will only increase. In general, the Zanstra method is known to systematically underestimate the stellar temperature, as this method assumes a black body stellar continuum which usually does not apply to such hot, high gravity stars. However, given that we are almost certainly observing the central star in scattered light, it is quite likely that this star may be a binary with a fairly hot companion.

With the continuum model fit described above, including the stellar continuum, the reddening curve was determined from the ratio of the model continuum to the observed continuum. The reddening curve was fitted in IRAF as a sixth order cubic spline, which osculated the upper envelope of the curve of Figure 6. As a comparison, the logarithm of this curve is plotted against the Whitford reddening curve, with the constant of the Whitford curve taken to be $c=1.2$. This value provides the best fit to the reddening curve, and also agrees with that previously determined from the Balmer decrement. The goodness of fit indicates that this method is another way

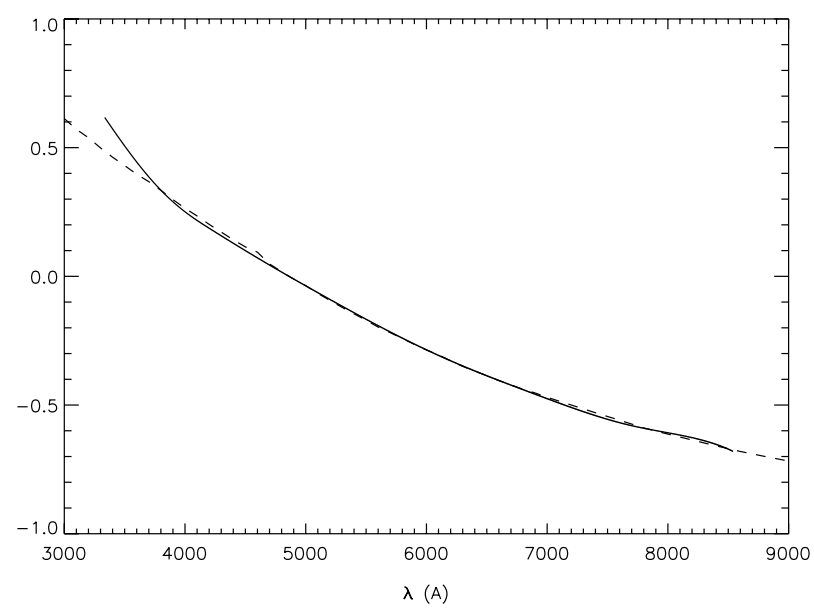

Figure 7 A comparison of the reddening curve for NGC $6302(-)$ and the Whitford reddening curve (- - -) with a logarithmic reddening constant $c=1.2$. in which the reddening constant can be calculated. As can be seen in Figure 7 the curves are remarkably similar, showing that the use of the Whitford curve for optical measurements of planetary nebulae proves a remarkably good approximation. However the two curves are systematically different at shorter wavelengths: the curve for NGC 6302 is much steeper in this region. We can take this as an indication there are many more small grains along our line of sight to NGC 6302 than would be the case in a typical sightline through the interstellar medium. These small grains are undoubtedly intrinsic to the nebula, having been earlier ejected by the central star, and possibly shattered in their passage through the nebula by grain-grain collisions.

\section{The Line Spectrum of NGC 6302}

With the reddening curve derived above, the full spectrum of NGC 6302 was dereddened, and the model continuum removed to leave us with a spectrum containing only the dereddened emission lines.

The measured wavelengths were then shifted to zero velocity by using a local fit to the known wavelengths of the hydrogen and helium recombination lines, or, in the scarcity or absence of these, to forbidden lines for which very accurate wavelengths are known (e.g. Dopita $\&$ Hua 1997). The flux and central wavelengths of each emission feature were then measured using the Gaussian fitting procedure in the IRAF task SPLOT, and a line identification was attempted. For this purpose the earlier spectrum of Aller et al. (1981) and the very nice work by Liu et al. (2000) were very helpful. Extensive use was also made of the web-based Atomic line list v2.04, at http://www.pa.uky.edu/ peter/atomic/.

The complete list of identifications, wavelengths, dereddened line fluxes, and estimated errors are given in Table 3 below for the nearly 600 emission lines detected. As mentioned in Section 2 several of the bright lines, including [O III], $\mathrm{H} \alpha$, and [N II] were grossly oversaturated in the long exposures. This left only the shortest exposures to measure the flux in these lines and the percentage errors in the measured fluxes are consequently larger than the measurement errors of many of the weaker lines.

The spectrum is incredibly rich, and would reward a detailed analysis, which is not within the scope of this paper. However, a number of interesting points are worth remarking on here.

First, the $\mathrm{He}(2-10)$ and $\mathrm{He}(2-8)$ Raman features are clearly visible at $\lambda 4331 \AA$ and $\lambda 4852 \AA$. These had only been reported previously in the PN NGC 7027 by Péquignot et al. (1997).

In addition, the Raman scattered O VI doublet by the enhanced hydrogenic cross-section near the $3^{2} \mathrm{P}$ level gives rise to velocity-broadened lines at 6830 and $7087 \AA$. The theory of this process was first described by Schmid (1989). The apparent line widths of 8.3 and $9 \AA$ FWHM respectively for these lines is an amplification of the Doppler line width of $\operatorname{Ly} \beta$ by a factor of about 6.7. This amplification is due to the difference in energy 
Table 3. Dereddened line fluxes in the core of NGC 6302 relative to $(\mathrm{H} \beta=100.0)$

\begin{tabular}{|c|c|c|c|c|c|}
\hline$\lambda_{0}$ & Ion & $\lambda_{\text {obs }}$ & $I(\lambda)$ & Error & Comment \\
\hline 3340.74 & O III & 3340.41 & 19.20 & \pm 3.0 & Bowen fluorescent line \\
\hline 3345.50 & {$[\mathrm{Ne} \mathrm{v}]$} & 3345.47 & 147.5 & \pm 15 & \\
\hline \multirow[t]{4}{*}{3362.20} & [Na IV] & 3362.07 & 1.196 & \pm 0.4 & \\
\hline & $?$ & 3381.07 & 0.498 & & \\
\hline & $?$ & 3385.23 & 0.219 & & \\
\hline & $?$ & 3392.17 & 0.147 & & \\
\hline \multirow[t]{2}{*}{3405.74} & O III & 3405.55 & 1.125 & \pm 0.3 & Bowen fluorescent line \\
\hline & $?$ & 3411.42 & 0.342 & & \\
\hline 3415.26 & O III & 3415.31 & 1.154 & & Bowen line \\
\hline \multirow[t]{2}{*}{3425.5} & {$[\mathrm{Ne} v]$} & 3425.87 & 534.1 & \pm 20 & \\
\hline & $?$ & 3434.02 & 0.380 & & \\
\hline 3444.05 & O III & 3444.09 & 34.22 & \pm 4 & Bowen fluorescent line \\
\hline 3466.5 & {$\left[\mathrm{~N}_{\mathrm{I}}\right]$} & 3466.61 & 2.118 & & \\
\hline 3467.54 & He I & & & & \\
\hline 3478.97 & He I & 3478.75 & 0.405 & \pm 0.04 & \\
\hline 3483.38 & $\mathrm{~N}_{\text {II }}$ & 3483.19 & 0.380 & \pm 0.06 & Blend $3.7 \AA ̊$ FWHM \\
\hline 3487.73 & $\mathrm{He} \mathrm{I}(42)+$ & 3488.18 & 0.605 & \pm 0.08 & Blend 2.9 $\mathrm{FWHM}$ \\
\hline 3488.7 & {$[\mathrm{Mg} \mathrm{VI}]$} & & & & \\
\hline 3498.64 & He I(40) & 3498.56 & 0.299 & \pm 0.016 & Blend \\
\hline 3502.36 & $\mathrm{He}+$ & 3502.01 & 0.305 & & \\
\hline 3502.0 & {$[\mathrm{Mg} \mathrm{VI}]$} & & & & \\
\hline 3512.51 & He I(38) & 3512.48 & 0.183 & & \\
\hline 3530.49 & He I(36) & 3530.55 & 0.222 & & \\
\hline 3554.40 & He I(34) & 3554.46 & 0.403 & \pm 0.025 & \\
\hline 3568.5 & $\mathrm{Ne}$ II & 3568.55 & 0.329 & \pm 0.02 & \\
\hline 3574.6 & $\mathrm{Ne}$ II & 3574.49 & 0.083 & \pm 0.006 & \\
\hline 3587.26 & He I(31) & 3587.04 & 0.640 & \pm 0.025 & \\
\hline 3613.64 & $\mathrm{He} \mathrm{I}(6)$ & 3613.70 & 0.528 & & \\
\hline 3631.3 & Si III & 3631.28 & 0.151 & & \\
\hline 3634.24 & He I(28) & 3634.36 & 0.718 & \pm 0.012 & \\
\hline 3671.47 & H I H24 & 3671.52 & & & \\
\hline 3673.76 & H I H23 & 3673.82 & & & \\
\hline 3676.36 & Н I H22 & 3676.41 & & & \\
\hline 3679.35 & Н I H21 & 3679.40 & 0.787 & \pm 0.05 & \\
\hline 3682.81 & H I H20 & 3682.85 & 0.931 & \pm 0.05 & \\
\hline 3686.83 & H I H19 & 3686.83 & 1.043 & \pm 0.05 & \\
\hline 3691.55 & H I H18 & 3691.59 & 1.173 & \pm 0.05 & \\
\hline 3694.21 & $\mathrm{Ne}$ II & 3694.98 & 0.123 & & \\
\hline 3697.15 & Н г H17 & 3697.14 & 1.397 & \pm 0.05 & \\
\hline 3703.85 & H I H16+ & 3704.26 & 2.845 & \pm 0.05 & Blend 2.4 ̊̊ FWHM \\
\hline 3705.00 & $\mathrm{He} \mathrm{I}$ & 3704.26 & & & \\
\hline 3711.97 & H I H15 & 3711.98 & 2.061 & \pm 0.05 & \\
\hline 3715.16 & He II(4-29) & 3715.25 & 0.161 & & \\
\hline 3717.2 & Si II & 3717.75 & 0.096 & & \\
\hline 3721.63 & {$[\mathrm{~S} \mathrm{III}]+$} & 3721.76 & 7.271 & \pm 0.17 & \\
\hline 3721.94 & HI H14+ & & & & \\
\hline 3720.40 & Не II(4-28) & 3721.78 & 7.319 & & \\
\hline 3726.03 & {$[\mathrm{O} \mathrm{II}]+$} & 3726.04 & 43.65 & \pm 3.0 & \\
\hline 3726.26 & He II(4-27) & & & & \\
\hline 3728.81 & {$[\mathrm{O} \mathrm{II}]$} & 3728.71 & 19.58 & \pm 1.7 & \\
\hline 3734.37 & Hi H13+ & 3734.32 & 3.136 & \pm 0.11 & \\
\hline 3732.83 & He II(4-26) & & & & \\
\hline 3736.81 & OIV & 3737.20 & 0.160 & & \\
\hline 3740.22 & He II(4-25) & 3740.17 & 0.187 & \pm 0.01 & \\
\hline & $?$ & 3743.31 & 0.037 & & \\
\hline 3748.60 & He II+(4-24) & & & & \\
\hline 3750.15 & Н I H12+ & 3750.13 & 3.494 & \pm 0.12 & \\
\hline lamda & He I(24) & & & & \\
\hline 3754.69 & N III+ & 3754.83 & 1.196 & \pm 0.09 & \\
\hline 3754.70 & O III & & & & \\
\hline 3759.88 & $\mathrm{OIII+}$ & 3759.83 & 6.255 & \pm 0.22 & \\
\hline 3758.14 & He II(4-23) & & & & \\
\hline 3770.63 & Hi H11+ & 3770.62 & 4.424 & \pm 0.10 & \\
\hline
\end{tabular}


Table 3. (Continued)

\begin{tabular}{|c|c|c|c|c|c|}
\hline$\lambda_{0}$ & Ion & $\lambda_{\mathrm{obs}}$ & $I(\lambda)$ & Error & Comment \\
\hline 3770.73 & $\mathrm{He}+$ & & & & \\
\hline 3769.07 & He II(4-22) & & & & \\
\hline 3774.02 & O III & 3774.12 & 0.155 & & \\
\hline 3777.42 & O II & 3777.32 & 0.033 & & \\
\hline 3781.68 & He II(4-21) & 3781.76 & 0.274 & \pm 0.02 & \\
\hline 3784.89 & $\mathrm{He} \mathrm{I}$ & 3784.63 & 0.070 & \pm 0.005 & \\
\hline 3791.28 & O III & 3791.33 & 0.316 & \pm 0.01 & \\
\hline 3796.33 & He II (4-20)+ & 3797.88 & 5.872 & \pm 0.20 & \\
\hline 3797.90 & H I H10 & & & & \\
\hline 3805.78 & He I & 3806.04 & 0.110 & \pm 0.01 & \\
\hline 3811 & O VI? & 3811.29 & 0.044 & & \\
\hline 3813.49 & He II $(4-19)+$ & 3813.50 & 0.399 & \pm 0.01 & \\
\hline 3813.54 & {$[\mathrm{Fe} \mathrm{VI}]$} & & & & \\
\hline 3819.61 & He I & 3819.93 & 1.671 & & \\
\hline 3833.80 & $\mathrm{He} \mathrm{II}(4-18)+$ & 3835.37 & 8.774 & & \\
\hline 3835.38 & Н г H9 & & & & \\
\hline 3839.79 & {$[\mathrm{Ni} \mathrm{v}]$} & 3839.96 & 0.108 & & \\
\hline 3842.81 & O II & 3843.07 & 0.427 & & \\
\hline 3853.7 & Si II & 3853.89 & 0.079 & \pm 0.01 & \\
\hline 3856.02 & Si II+ & 3856.05 & 0.506 & & \\
\hline 3856.59 & Si II+ & & & & \\
\hline 3856.13 & O II & & & & \\
\hline 3858.07 & He II(4-17) & 3858.09 & 0.559 & & \\
\hline 3862.60 & Si II & 3862.77 & 1.667 & \pm 0.13 & \\
\hline 3869.06 & {$[\mathrm{Ne} I I I]+$} & 3868.76 & 210.8 & \pm 6.0 & \\
\hline \multirow[t]{2}{*}{3867.48} & $\mathrm{He} \mathrm{I}$ & & & & \\
\hline & $?$ & 3880.20 & 1.412 & & \\
\hline 3887.44 & He II $(4-16)+$ & 3888.82 & 23.89 & \pm 0.35 & \\
\hline 3888.64 & $\mathrm{He}+$ & & & & \\
\hline \multirow[t]{2}{*}{3889.05} & H I H8 & & & & \\
\hline & $?$ & 3895.3 & 0.144 & \pm 0.05 & Blend 4.6 ̊̊ FWHM \\
\hline 3923.48 & He II(4-15) & 3923.44 & 0.698 & \pm 0.03 & \\
\hline 3926.55 & He I & 3926.85 & 0.298 & \pm 0.03 & \\
\hline 3933.66 & Ca II & 3933.52 & & & seen in absorption \\
\hline 3935.95 & He I & 3936.07 & 0.047 & & \\
\hline 3950.31 & [Ni III] & 3950.42 & 0.174 & \pm 0.015 & \\
\hline 3956.64 & Si III & 3956.62 & 0.064 & & \\
\hline 3964.73 & He I & 3964.80 & 1.300 & & Uncertain: on wing of [ $\mathrm{Ne} \mathrm{III}]$ line \\
\hline 3967.79 & [Ne III]+ & 3967.44 & 59.50 & \pm 1.70 & \\
\hline 3968.43 & He II(4-14) & & & & \\
\hline 3970.07 & Hi H7 & 3970.12 & 16.00 & & \\
\hline 3994.62 & {$[\mathrm{Fe} \mathrm{VI}]+$} & 3994.80 & 0.056 & \pm 0.008 & Blend $2.2 \AA$ FWHM \\
\hline 3994.99 & N II & & & & \\
\hline 3997.88 & {$[\mathrm{Cav}]+$} & 3997.97 & 0.055 & \pm 0.008 & Blend 3.1 ̊ FWHM \\
\hline 3998.63 & N III & & & & \\
\hline 4003.58 & $\mathrm{~N}_{\text {III }}$ & 4003.33 & 0.038 & & \\
\hline 4009.25 & He I & 4009.25 & 0.292 & & \\
\hline 4011.1 & $\mathrm{Ni}+$ & 4011.27 & 0.070 & & \\
\hline 4011.6 & C III & & & & \\
\hline 4018.1 & $\mathrm{~N}_{\text {II }}$ & 4018.17 & 0.086 & \pm 0.007 & \\
\hline 4025.6 & He II $(4-13)+$ & 4025.98 & 4.102 & \pm 0.11 & \\
\hline 4026.19 & $\mathrm{He} \mathrm{I}$ & & & & \\
\hline 4035.08 & $\mathrm{~N}_{\mathrm{I}}$ & 4034.72 & 0.052 & \pm 0.005 & Blend 2.8 Å FWHM \\
\hline 4041.31 & $\mathrm{~N}_{\text {II }}$ & 4041.31 & 0.070 & \pm 0.013 & \\
\hline 4043.53 & $\mathrm{~N}_{\text {II }}$ & 4043.56 & 0.028 & & \\
\hline 4060.2 & {$[\mathrm{~F}$ IV $]+$} & 4060.22 & 0.045 & & Blend 2.8 $\mathrm{A}$ FWHM \\
\hline 4062.90 & $\mathrm{O}_{\text {II }}$ & & & & \\
\hline 4068.60 & {$\left[\mathrm{~S}_{\mathrm{II}}\right]+$} & 4068.61 & 16.29 & \pm 0.13 & \\
\hline 4069.62 & $\mathrm{OII+}$ & & & & \\
\hline 4071.23 & $\mathrm{O} \mathrm{II}+$ & 4071.64 & 0.237 & & \\
\hline 4072.16 & $\mathrm{O} \mathrm{II}+$ & & & & \\
\hline 4075.86 & O II & 4074.15 & 0.215 & & \\
\hline \multirow[t]{2}{*}{4076.35} & {$[\mathrm{~S}$ II]+ } & 4076.41 & 5.487 & \pm 0.15 & \\
\hline & & & & & (continued) \\
\hline
\end{tabular}


Table 3. (Continued)

\begin{tabular}{|c|c|c|c|c|c|}
\hline$\lambda_{0}$ & Ion & $\lambda_{\mathrm{obs}}$ & $I(\lambda)$ & Error & Comment \\
\hline 4078.84 & OII & & & & \\
\hline 4083.90 & $\mathrm{OII}+$ & 4084.46 & 0.041 & & \\
\hline 4085.06 & O II & & & & \\
\hline 4089.29 & OII & 4089.00 & 0.060 & \pm 0.005 & \\
\hline 4092.93 & OII & 4093.80 & 0.033 & & \\
\hline 4097.33 & $\mathrm{~N}$ III+ & 4097.30 & 3.852 & & \\
\hline 4097.25 & $\mathrm{O}$ II + & & & & \\
\hline 4097.26 & $\mathrm{O}$ II + & & & & \\
\hline 4098.24 & $\mathrm{O} \mathrm{II}+$ & & & & \\
\hline 4100.04 & He II(4-12)+ & & & & \\
\hline 4101.73 & $\mathrm{H} \delta$ & 4101.76 & 29.27 & \pm 0.8 & \\
\hline 4120.82 & $\mathrm{He}+$ & 4121.16 & 0.479 & \pm 0.08 & \\
\hline 4121.3 & $\mathrm{~N}_{\text {II }}$ & & & & \\
\hline 4123.46 & $\mathrm{~N}$ II? & 4123.02 & 0.355 & & \\
\hline 4129.32 & O II & 4129.04 & 0.034 & & \\
\hline 4132.80 & O II & 4132.86 & 0.061 & & \\
\hline 4144.32 & {$[\mathrm{Fe} \mathrm{III}]+$} & 4144.20 & 0.501 & & \\
\hline 4143.76 & $\mathrm{He} \mathrm{I}$ & & & & \\
\hline 4153.30 & O II & 4153.15 & 0.051 & \pm 0.013 & Blend $3.2 \AA$ FWHM \\
\hline 4157.75 & {$[\mathrm{~F} \mathrm{II}]+$} & 4156.56 & 0.084 & \pm 0.008 & \\
\hline 4156.53 & O II & & & & \\
\hline 4163.33 & {$[\mathrm{Kv}]$} & 4163.46 & 0.584 & \pm 0.008 & \\
\hline 4168.97 & $\mathrm{He}+$ & 4169.28 & 0.110 & \pm 0.008 & \\
\hline 4169.22 & O II & & & & \\
\hline \multirow[t]{2}{*}{4176.16} & $\mathrm{~N}_{\text {II }}$ & 4175.76 & 0.055 & \pm 0.008 & \\
\hline & $?$ & 4178.32 & 0.035 & & \\
\hline 4180.9 & {$[\mathrm{Fe} \mathrm{v}]$} & 4181.00 & 0.066 & \pm 0.008 & \\
\hline 4186.8 & C III & 4186.81 & 0.141 & \pm 0.013 & Blend 2.9 $\mathrm{FWHM}$ \\
\hline 4189.7 & O II & 4189.94 & 0.071 & & \\
\hline 4195.6 & $\mathrm{~N}_{\text {III }}$ & 4195.63 & 0.158 & & \\
\hline 4199.83 & He II(4-11) & 4199.79 & 1.859 & & \\
\hline 4227.5 & [Ni III] & 4228.00 & 0.202 & & \\
\hline 4241.48 & {$[\mathrm{Mn}$ III $]+$} & 4241.31 & 0.047 & & \\
\hline \multirow{2}{*}{4241.79} & N II & & & & \\
\hline & $?$ & 4255.91 & 0.156 & & \\
\hline 4267.13 & $\mathrm{C}_{\text {II }}$ & 4267.00 & 0.080 & \pm 0.008 & \\
\hline 4273.06 & O II & 4272.96 & 0.077 & & \\
\hline 4275.5 & $\mathrm{O} \mathrm{II}+$ & 4276.24 & 0.057 & & Blend $2.5 \AA$ FWHM \\
\hline 4276.7 & O II & & & & \\
\hline 4282.91 & $\mathrm{OII}+$ & 4283.05 & 0.043 & & \\
\hline 4283.68 & O II & & & & \\
\hline 4287.39 & {$[\mathrm{Fe} \mathrm{II}]$} & 4287.41 & 0.041 & & \\
\hline 4294.76 & O II & 4294.12 & 0.063 & & Blend 3.6 $\mathrm{FWHM}$ \\
\hline 4317.14 & $\mathrm{O}$ IIt & 4318.55 & 0.048 & & \\
\hline 4319.63 & O II & & & & \\
\hline 4331 & $\begin{array}{l}\operatorname{He}(2-10) \\
(\operatorname{Raman})\end{array}$ & 4331.30 & 0.070 & & $\begin{array}{l}\text { Broad He Raman feature: see } \\
\text { Péquionnot et al } 1997\end{array}$ \\
\hline 4338.67 & He II(4-10)+ & & & & \\
\hline 4340.46 & $\mathrm{H} \gamma$ & 4340.45 & 43.74 & \pm 1.2 & \\
\hline 4345.56 & O II & 4345.26 & $(0.15)$ & & Uncertain: on strong line wing \\
\hline 4359.34 & {$[\mathrm{Fe} \mathrm{II}]$} & 4359.28 & $(0.14)$ & & Uncertain: on strong line wing \\
\hline 4363.21 & [O III $]$ & 4363.23 & 38.18 & & \\
\hline \multirow[t]{2}{*}{4366.89} & O II & 4367.96 & $(0.16)$ & & Uncertain: on strong line wing \\
\hline & $?$ & 4376.48 & 0.066 & & \\
\hline 4379.2 & N III & 4378.87 & 0.270 & & \\
\hline 4387.8 & He I & 4387.83 & 0.643 & & \\
\hline $4400-4417$ & $\mathrm{O} I+\mathrm{Ne}$ II & 4413.77 & 0.554 & & Blend of many lines, $11.8 \AA \AA$ FWHM \\
\hline 4431.82 & $\mathrm{~N}_{\text {II }}$ & 4431.62 & 0.164 & & \\
\hline 4437.55 & $\mathrm{He}$ I & 4437.53 & 0.111 & \pm 0.008 & \\
\hline 4452.37 & $\mathrm{OII}+?$ & 4453.07 & 0.152 & & Blend $4.3 \AA \mathrm{FWHM}$ \\
\hline 4471.47 & He I & 4471.45 & 5.428 & \pm 0.1 & \\
\hline 4491.2 & O II & 4491.11 & 0.055 & & \\
\hline \multirow[t]{2}{*}{4492.64} & {$[\mathrm{Fe} \mathrm{II}]$} & 4493.09 & 0.058 & & \\
\hline & & & & & (continued) \\
\hline
\end{tabular}


Table 3. (Continued)

\begin{tabular}{|c|c|c|c|c|c|}
\hline$\lambda_{0}$ & Ion & $\lambda_{\mathrm{obs}}$ & $I(\lambda)$ & Error & Comment \\
\hline 4498.04 & {$[\mathrm{Mn}$ IV $]$} & 4498.60 & 0.083 & \pm 0.02 & \\
\hline 4510.92 & {$[\mathrm{~K}$ IV $]+$} & 4510.72 & 0.208 & \pm 0.02 & \\
\hline 4510.91 & $\mathrm{~N}_{\text {III }}$ & & & & \\
\hline 4514.6 & N III & 4514.74 & 0.097 & \pm 0.025 & \\
\hline 4518.15 & N III & 4518.32 & 0.082 & \pm 0.015 & \\
\hline 4519.62 & $\mathrm{~N}_{\text {II }}$ & 4519.69 & 0.119 & & \\
\hline 4519.63 & O III & 4519.48 & 0.105 & & \\
\hline $4518-4525$ & N III, C III & 4522.86 & 0.128 & & Blend of N III, C III, $5 \AA \AA$ FWHM \\
\hline 4523.6 & N III & 4523.57 & 0.071 & \pm 0.025 & \\
\hline 4529.09 & [Mn IV] & 4529.23 & 0.080 & & \\
\hline 4530.42 & $\mathrm{~N}_{\text {II }}$ & 4530.30 & 0.104 & \pm 0.035 & \\
\hline 4534.57 & $\mathrm{~N}_{\text {III }}$ & 4534.56 & 0.071 & \pm 0.025 & \\
\hline 4541.59 & He II(4-9) & 4541.53 & 2.540 & \pm 0.035 & \\
\hline 4549.04 & {$[\mathrm{Mn}$ IV $]$} & 4549.53 & 0.064 & \pm 0.035 & \\
\hline 4552.53 & $\mathrm{~N}_{\text {II }}$ & 4552.54 & 0.033 & & \\
\hline 4554.0 & Ba II & 4553.51 & 0.104 & & \\
\hline 4563.85 & [Mn IV] & 4563.10 & 0.045 & & \\
\hline 4566.60 & [Mn III] & 4566.62 & 0.067 & & \\
\hline 4571.1 & $\mathrm{Mg} \mathrm{I}]$ & 4579.97 & 0.233 & & \\
\hline 4591.66 & [Mn IV] & 4591.28 & 0.047 & & \\
\hline 4596.18 & $\mathrm{O}_{\text {II }}$ & 4596.14 & 0.038 & & \\
\hline 4603.74 & $\mathrm{~N} \mathrm{v}$ & 4603.21 & 0.094 & & \\
\hline 4607.06 & {$[\mathrm{Fe} \mathrm{III}]+$} & 4606.59 & 0.686 & \pm 0.02 & \\
\hline 4607.16 & N II & & & & \\
\hline 4609.66 & O II & 4609.67 & 0.047 & & \\
\hline 4611.59 & O II & 4611.66 & 0.070 & & \\
\hline 4613.87 & $\mathrm{~N}$ II + & 4613.75 & 0.101 & & \\
\hline 4613.68 & O II & 4613.19 & 0.183 & & \\
\hline 4615.65 & {$[\mathrm{CoI}]$} & 4615.64 & 0.102 & & \\
\hline 4619.97 & $\mathrm{Nv}$ & 4619.57 & 0.062 & & \\
\hline 4624.92 & [Arv] & 4624.92 & 0.397 & \pm 0.020 & \\
\hline 4629.39 & [Fe III] & 4629.54 & 0.056 & & \\
\hline 4634.14 & N III & 4634.10 & 2.926 & & \\
\hline 4640.64 & N III & 4640.49 & 6.112 & \pm 0.022 & \\
\hline 4644.1 & C III+ & 4646.42 & 0.110 & & Blend \\
\hline 4646.93 & $\mathrm{~N} I I+$ & & & & \\
\hline 4647.42 & C III+ & & & & \\
\hline 4647.80 & $\mathrm{OII}+$ & & & & \\
\hline 4649.13 & O II & 4649.39 & 0.232 & & \\
\hline 4658.10 & [Fe III] & 4657.87 & 0.418 & \pm 0.015 & \\
\hline 4661.63 & O II & 4661.76 & 0.118 & & \\
\hline 4676.26 & $\mathrm{O}_{\mathrm{II}}$ & 4675.83 & 0.091 & & \\
\hline 4685.71 & He II(3-4) & 4685.82 & 67.49 & \pm 0.15 & \\
\hline \multirow[t]{2}{*}{4701.62} & [Fe III] & 4701.61 & 0.098 & \pm 0.02 & \\
\hline & $?$ & 4707.31 & 0.125 & & \\
\hline 4711.37 & [Ar IV]+ & 4711.35 & 12.04 & \pm 0.10 & \\
\hline 4711.9 & [Ne IV] & & & & \\
\hline 4713.14 & He I & 4713.51 & 3.020 & \pm 0.10 & \\
\hline 4724.15 & [Ne IV]+ & 4724.82 & 3.686 & \pm 0.13 & \\
\hline 4725.62 & [Ne IV] & & & & \\
\hline 4733.90 & [Fe III] & 4733.97 & 0.057 & \pm 0.02 & \\
\hline 4740.16 & [Ar IV] & 4740.20 & 18.75 & \pm 0.10 & \\
\hline 4754.80 & [Fe III] & 4754.47 & 0.070 & \pm 0.008 & \\
\hline 4769.40 & {$[\mathrm{Fe} \mathrm{III}]$} & 4769.40 & 0.050 & \pm 0.008 & \\
\hline 4777.7 & [Fe III] & 4777.86 & 0.025 & & \\
\hline 4788.13 & $\mathrm{~N}_{\text {II }}$ & 4788.32 & 0.052 & & \\
\hline 4803.29 & $\mathrm{~N}_{\text {II }}$ & 4802.91 & 0.070 & & \\
\hline 4814.55 & [Fe II] & 4814.48 & 0.050 & & \\
\hline 4852 & $\begin{array}{l}\operatorname{He}(2-8) \\
\text { (Raman) }\end{array}$ & 4852.22 & 0.470 & & $\begin{array}{l}\text { He Raman feature: } 5 \AA \text { FWHM, see } \\
\text { Péquignot et al. } 1997\end{array}$ \\
\hline 4859.32 & Не II $(4-8)+$ & & & & \\
\hline 4861.32 & $\mathrm{H} \beta$ & 4861.30 & 100.0 & \pm 0.3 & $\begin{array}{l}\text { Error: measurement error only } \\
\text { (for systematic errors, see text) }\end{array}$ \\
\hline
\end{tabular}


Table 3. (Continued)

\begin{tabular}{|c|c|c|c|c|c|}
\hline$\lambda_{0}$ & Ion & $\lambda_{\mathrm{obs}}$ & $I(\lambda)$ & Error & Comment \\
\hline \multirow[t]{4}{*}{4889.6} & {$[\mathrm{Fe}$ II $]$} & 4889.55 & 0.031 & \pm 0.005 & \\
\hline & $?$ & 4893.60 & 0.059 & & \\
\hline & ? & 4902.62 & 0.052 & & \\
\hline & ? & 4906.49 & 0.071 & & \\
\hline 4921.93 & He I & 4921.94 & 1.562 & & \\
\hline \multirow[t]{3}{*}{4931.23} & [O III $]$ & 4930.83 & 0.381 & & \\
\hline & $?$ & 4938.64 & 0.075 & & Blend? \\
\hline & ? & 4944.60 & 0.314 & & \\
\hline 4958.91 & [O III $]$ & 4958.86 & 380.8 & \pm 1 & \\
\hline 4987.20 & {$[\mathrm{Fe}$ III $]$} & 4988.76 & 0.123 & \pm 0.01 & \\
\hline 4994.36 & N II & 4994.84 & 0.077 & & \\
\hline 5006.73 & [O III $]$ & 5006.73 & 1055 & \pm 3 & \\
\hline 5015.68 & He I & 5016.33 & (2.0) & & Measurement difficult; on line wing \\
\hline 5032.43 & S II & 5032.60 & 0.056 & \pm 0.005 & \\
\hline 5041.03 & Si II & 5041.00 & 1.704 & & \\
\hline 5047.74 & He I & 5047.9 & 0.250 & & Wavelength scale suspect $5040-5180$ \\
\hline 5055.98 & Si II + & 5056.20 & 0.758 & & \\
\hline \multirow{2}{*}{5056.31} & Si II & & & & \\
\hline & $?$ & 5074.5 & 0.012 & & \\
\hline 5084.8 & [Fe III $]$ & 5086.9 & 0.037 & \pm 0.005 & \\
\hline 5103.30 & S II & 5103.1 & 0.033 & & \\
\hline \multirow[t]{3}{*}{5111.63} & {$[\mathrm{Fe} \mathrm{II}]$} & 5112.2 & 0.028 & \pm 0.006 & \\
\hline & $?$ & 5132.1 & 0.031 & & \\
\hline & $?$ & 5150.0 & 0.053 & & \\
\hline 5158.77 & {$[\mathrm{Fe} \mathrm{II}]$} & 5157.6 & 0.116 & & \\
\hline 5176.4 & {$[\mathrm{Fe} \mathrm{VI}]$} & 5176.0 & 0.242 & & \\
\hline 5191.82 & [Ar III] & 5191.80 & 0.266 & \pm 0.02 & \\
\hline 5197.90 & {$\left[\mathrm{~N}_{\mathrm{I}}\right]$} & 5197.88 & 4.457 & \pm 0.06 & \\
\hline 5200.26 & {$\left[\mathrm{~N}_{\mathrm{I}}\right]$} & 5200.88 & 3.310 & & \\
\hline \multirow[t]{2}{*}{5220.06} & [Fe II] & 5219.61 & 0.020 & \pm 0.005 & \\
\hline & $?$ & 5233.60 & 0.015 & & \\
\hline 5261.62 & {$[\mathrm{Fe} \mathrm{II}]$} & 5261.42 & 0.105 & & \\
\hline 5270.40 & {$[\mathrm{Fe}$ III $]$} & 5270.38 & 0.107 & & \\
\hline 5273.38 & {$[\mathrm{Fe}$ II $]$} & 5273.24 & 0.024 & \pm 0.004 & \\
\hline 5277.8 & {$[\mathrm{Fe} \mathrm{VI}]$} & 5276.95 & 0.093 & \pm 0.006 & \\
\hline 5289.79 & {$[\mathrm{Fe} \mathrm{VI}]$} & 5290.44 & 0.219 & \pm 0.008 & \\
\hline 5296.82 & {$[\mathrm{Fe} \mathrm{II}]+$} & 5298.63 & 0.037 & & \\
\hline \multirow[t]{2}{*}{5298.87} & {$[\mathrm{Fe} \mathrm{II}]$} & & & & \\
\hline & $?$ & 5304.51 & 0.015 & & \\
\hline 5309.11 & {$[\mathrm{Cav}]$} & 5309.26 & 0.310 & \pm 0.01 & \\
\hline 5323.30 & [Cliv] & 5323.15 & 0.188 & & \\
\hline 5335.18 & {$[\mathrm{Fe} \mathrm{VI}]$} & 5335.25 & 0.107 & & Blend 3.0 ̊ FWHM \\
\hline \multirow[t]{2}{*}{5346} & [Kr IV] & 5346.10 & 0.020 & & \\
\hline & $?$ & 5359.40 & 0.013 & & \\
\hline \multirow[t]{2}{*}{5364} & {$[\mathrm{Rb} v]$} & 5363.24 & 0.012 & & \\
\hline & $?$ & 5371.29 & 0.016 & & \\
\hline 5376.45 & {$[\mathrm{Fe} \mathrm{II}]$} & 5376.37 & 0.015 & \pm 0.002 & \\
\hline 5411.53 & Не II $(4-7)$ & 5411.49 & 7.327 & \pm 0.01 & \\
\hline 5423.9 & {$[\mathrm{Fe} \mathrm{VI}]$} & 5424.37 & 0.049 & & \\
\hline 5426.6 & {$[\mathrm{Fe} \mathrm{VI}]$} & 5426.62 & 0.017 & & \\
\hline 5433.13 & {$[\mathrm{Fe} \mathrm{II}]$} & 5432.75 & 0.004 & & \\
\hline \multirow[t]{3}{*}{5460.69} & [Ca vI] & 5460.64 & 0.024 & \pm 0.002 & \\
\hline & $?$ & 5467.31 & 0.027 & \pm 0.002 & \\
\hline & $?$ & 5470.24 & 0.010 & & \\
\hline \multirow[t]{2}{*}{5484.9} & {$[\mathrm{Fe} \mathrm{VI}]$} & 5484.81 & 0.031 & \pm 0.002 & \\
\hline & $?$ & 5494.30 & 0.004 & & \\
\hline \multirow{3}{*}{$\begin{array}{l}5495.70 \\
5495.72\end{array}$} & $\mathrm{~N}$ II+ & 5495.39 & 0.005 & & \\
\hline & {$[\mathrm{Fe}$ II $]$} & & & & \\
\hline & ! & 5506.92 & 0.006 & & \\
\hline 5527.33 & {$[\mathrm{Fe}$ II] } & 552605 & 0.404 & $\begin{array}{l}+0.004 \\
+0.002\end{array}$ & \\
\hline 5530.24 & $\mathrm{~N}_{\text {II }}$ & 5530.16 & 0.019 & \pm 0.003 & \\
\hline \multirow{2}{*}{5537.60} & [Cl III] & 5537.71 & 1.099 & \pm 0.004 & \\
\hline & & & & & (continued) \\
\hline
\end{tabular}


Table 3. (Continued)

\begin{tabular}{|c|c|c|c|c|c|}
\hline$\lambda_{0}$ & Ion & $\lambda_{\mathrm{obs}}$ & $I(\lambda)$ & Error & Comment \\
\hline 5543.81 & $\mathrm{CI}_{\mathrm{I}}$ & 5543.94 & 0.015 & \pm 0.003 & \\
\hline 5551.95 & $\mathrm{~N}_{\text {II }}$ & 5551.88 & 0.025 & \pm 0.003 & \\
\hline 5555.03 & OI & 5555.90 & 0.006 & \pm 0.002 & \\
\hline 5568.35 & Si II & 5568.42 & 0.009 & & \\
\hline 5577.34 & [O I] & 5577.30 & 0.279 & \pm 0.006 & \\
\hline \multirow[t]{2}{*}{5592.37} & O III & 5592.12 & 0.074 & \pm 0.005 & \\
\hline & $?$ & 5597.57 & 0.009 & \pm 0.001 & \\
\hline \multirow[t]{3}{*}{5602.3} & {$[\mathrm{~K}$ VI] } & 5602.04 & 0.110 & \pm 0.004 & \\
\hline & $?$ & 5618.70 & 0.032 & & \\
\hline & $?$ & 5622.10 & 0.040 & & \\
\hline 5631.07 & {$[\mathrm{Fe} \mathrm{VI}]$} & 5630.99 & 0.052 & & \\
\hline 5644.80 & {$[\mathrm{Fe}$ IV $]$} & 5645.02 & 0.007 & & \\
\hline 5666.63 & $\mathrm{~N}_{\text {II }}$ & 5666.65 & 0.089 & \pm 0.008 & \\
\hline 5676.02 & N II + & 5676.67 & 0.061 & & \\
\hline 5677 & {$[\mathrm{Fe} \mathrm{VI}]$} & & & & \\
\hline 5679.56 & $\mathrm{~N}_{\text {II }}$ & 5679.50 & 0.154 & & \\
\hline 5686.21 & $\mathrm{~N}_{\text {II }}$ & 5686.07 & 0.017 & & \\
\hline 5692.04 & {$[\mathrm{Fe}$ IV $]+$} & 5692.07 & 0.035 & & \\
\hline 5693.56 & [Mn v] & & & & \\
\hline 5703.4 & {$[\mathrm{Mn} \mathrm{v}]$} & 5702.08 & 0.063 & \pm 0.001 & \\
\hline 5710.77 & $\mathrm{~N}_{\text {II }}$ & 5710.71 & 0.023 & \pm 0.001 & \\
\hline 5721.1 & {$[\mathrm{Fe}$ VII] } & 5721.19 & 0.277 & \pm 0.001 & \\
\hline 5739.73 & Si III & 5739.42 & 0.012 & \pm 0.001 & \\
\hline 5754.60 & {$[\mathrm{~N} \mathrm{II}]$} & 5754.81 & 23.18 & \pm 0.05 & \\
\hline 5784.94 & He II (5-40) & 5785.15 & 0.027 & & \\
\hline 5801.51 & $\mathrm{CIV}+$ & 5800.65 & 0.124 & & \\
\hline 5800.48 & $\mathrm{He} \mathrm{II}(5-37)$ & & & & \\
\hline 5806.57 & He II $(5-36)$ & 5806.27 & 0.050 & & \\
\hline 5812.14 & $\mathrm{CIV}+$ & 5812.52 & 0.058 & & Blend $2.50 \AA ̊$ FWHM \\
\hline 5813.19 & $\mathrm{He} \mathrm{II}(5-35)$ & & & & \\
\hline 5820.43 & He II (5-34) & 5820.31 & 0.046 & & \\
\hline 5828.36 & He II (5-33) & 5828.21 & 0.038 & & \\
\hline 5837.06 & He II $(5-32)$ & 5836.88 & 0.050 & & \\
\hline \multirow[t]{2}{*}{5847.25} & He II $(5-31)$ & 5846.58 & 0.046 & & \\
\hline & $?$ & 5852.73 & 0.061 & & \\
\hline \multirow{2}{*}{5857.26} & He II $(5-30)$ & 5857.23 & 0.064 & \pm 0.01 & \\
\hline & $?$ & 5861.39 & 0.078 & & \\
\hline 5862.6 & {$[\mathrm{Mnv}]+$} & 5864.10 & 0.009 & \pm 0.003 & \\
\hline 5869.02 & $\mathrm{He} \mathrm{II}(5-29)$ & 5869.09 & 0.080 & \pm 0.01 & \\
\hline 5875.66 & $\mathrm{He} \mathrm{I}$ & 5875.65 & 20.35 & \pm 0.4 & \\
\hline 5882.12 & $\mathrm{He}$ II (5-28) & 5881.99 & 0.051 & & \\
\hline 5896.78 & He II (5-27) & 5895.55 & 0.064 & \pm 0.01 & \\
\hline \multirow[t]{2}{*}{5913.24} & He II (5-26) & 5913.27 & 0.085 & \pm 0.006 & \\
\hline & $?$ & 5921.97 & 0.006 & & \\
\hline 5927.81 & $\mathrm{~N}_{\text {II }}$ & 5927.66 & 0.011 & \pm 0.002 & \\
\hline 5931.78 & $\mathrm{~N}$ II + & 5931.89 & 0.091 & \pm 0.002 & \\
\hline 5931.83 & He II (5-25) & & & & \\
\hline \multirow[t]{2}{*}{5941.65} & $\mathrm{~N}_{\text {II }}$ & 5941.23 & 0.022 & \pm 0.001 & \\
\hline & $?$ & 5945.27 & 0.012 & \pm 0.002 & Possible blend? \\
\hline 5952.93 & He II (5-24) & 5952.90 & 0.104 & & \\
\hline \multirow[t]{3}{*}{5957.56} & Si II & 5957.60 & 0.011 & & Blend $4 \AA$ FWHM \\
\hline & $?$ & 5961.69 & 0.031 & & \\
\hline & $?$ & 5969.23 & 0.009 & & \\
\hline 5977.03 & He II (5-23) & 5977.18 & 0.122 & & \\
\hline \multirow[t]{3}{*}{5978.93} & Si II & 5977.08 & 0.119 & \pm 0.002 & \\
\hline & $?$ & 5980.58 & 0.012 & & \\
\hline & $?$ & 5989.55 & 0.014 & \pm 0.002 & \\
\hline 6004.72 & He II (5-22) & 6004.66 & 0.118 & & \\
\hline 6024.40 & {$[\mathrm{Mn} \mathrm{v}]$} & 6024.81 & 0.015 & & \\
\hline 6036.78 & He II $(5-21)$ & 6037.19 & 0.139 & & \\
\hline 6074.19 & He II $(5-20)$ & 6074.20 & 0.174 & & \\
\hline 6084.9 & {$[\mathrm{Mn} \mathrm{v}]$} & 6083.64 & 0.044 & & \\
\hline \multirow[t]{2}{*}{6086.40} & {$[\mathrm{Ca} \mathrm{v}]$} & 6086.64 & 0.464 & & \\
\hline & & & & & (continued) \\
\hline
\end{tabular}


Table 3. (Continued)

\begin{tabular}{|c|c|c|c|c|c|}
\hline$\lambda_{0}$ & Ion & $\lambda_{\mathrm{obs}}$ & $I(\lambda)$ & Error & Comment \\
\hline 6101.8 & {$[\mathrm{~K} I V]$} & 6101.33 & 0.756 & \pm 0.002 & \\
\hline 6118.26 & He II (5-19) & 6118.26 & 0.179 & \pm 0.002 & \\
\hline \multirow[t]{2}{*}{6131} & {$[\mathrm{Br} \mathrm{III}]$} & 6130.53 & 0.004 & & \\
\hline & $?$ & 6134.47 & 0.007 & \pm 0.001 & Blend 2.7 Å FWHM \\
\hline 6141.7 & Ba II & 6141.66 & 0.008 & & \\
\hline 6151.43 & $\mathrm{C}_{\text {II }}$ & 6150.95 & 0.009 & & \\
\hline 6157.6 & [Mn v] & 6157.44 & 0.036 & \pm 0.002 & \\
\hline \multirow{2}{*}{6161.83} & {$[\mathrm{Cl} \mathrm{II}]$} & 6161.8 & 0.011 & & \\
\hline & $?$ & 6165.75 & 0.029 & & \\
\hline 6167.7 & {$[\mathrm{Mnv}]$} & 6167.70 & 0.008 & & \\
\hline \multirow[t]{3}{*}{6170.69} & Не II (5-18) & 6170.67 & 0.212 & & \\
\hline & $?$ & 6198.31 & 0.022 & & \\
\hline & $?$ & 6200.06 & 0.048 & & Blend 3.3 Å FWHM \\
\hline 6218.4 & {$[\mathrm{Mn} v]$} & 6218.88 & 0.026 & \pm 0.002 & \\
\hline 6219.2 & {$[\mathrm{Mn} \mathrm{v}]$} & 6221.58 & 0.026 & \pm 0.002 & \\
\hline 6228.6 & {$[\mathrm{~K}$ VI] } & 6228.26 & 0.200 & & \\
\hline \multirow{4}{*}{6233.82} & Не II $(5-17)$ & 6233.78 & 0.251 & & \\
\hline & $?$ & 6273.19 & 0.011 & & \\
\hline & $?$ & 6277.89 & 0.114 & & \\
\hline & $?$ & 6289.59 & 0.018 & \pm 0.002 & \\
\hline 6300.30 & {$\left[\mathrm{O}_{\mathrm{I}}\right]$} & 6300.40 & 22.31 & \pm 0.4 & \\
\hline \multirow[t]{2}{*}{6312.10} & {$[\mathrm{~S} \mathrm{III}]$} & 6312.06 & 6.581 & \pm 0.15 & \\
\hline & $?$ & 6341.30 & 0.028 & & \\
\hline 6345.4 & {$[\mathrm{Mn} \mathrm{v}] ?$} & 6343.55 & 0.055 & \pm 0.006 & \\
\hline 6347.09 & Si II & 6347.18 & 0.398 & & \\
\hline 6363.78 & {$[\mathrm{O}$ I $]$} & 6363.70 & 7.839 & \pm 0.15 & \\
\hline \multirow[t]{2}{*}{6371.36} & Si II & 6371.27 & 0.893 & & \\
\hline & $?$ & 6383.70 & 0.005 & & \\
\hline \multirow[t]{2}{*}{6393.7} & {$[\mathrm{Mn} v]$} & 6393.55 & 0.068 & & \\
\hline & $?$ & 6402.28 & 0.001 & & \\
\hline \multirow[t]{2}{*}{6406.38} & Не II $(5-15)$ & 6406.17 & 0.365 & & \\
\hline & $?$ & 6412.21 & 0.052 & & \\
\hline 6427.1 & {$[\mathrm{Ca} \mathrm{v}]$} & 6426.87 & 0.004 & \pm 0.001 & \\
\hline \multirow[t]{5}{*}{6434.73} & [Arv] & 6434.76 & 5.314 & & \\
\hline & $?$ & 6444.23 & 0.006 & & Blend 3.6 Å FWHM \\
\hline & $?$ & 6451.69 & 0.011 & \pm 0.001 & \\
\hline & $?$ & 6455.09 & 0.007 & \pm 0.001 & Blend $2.5 \AA ̊ F W H M$ \\
\hline & $?$ & 6460.81 & 0.031 & \pm 0.003 & Blend 2.8 Å FWHM \\
\hline 6465.95 & Si I? & 6466.02 & 0.032 & \pm 0.003 & \\
\hline \multirow[t]{2}{*}{6473.86} & {$[\mathrm{Fe} \mathrm{II}]$} & 6473.83 & 0.023 & & \\
\hline & $?$ & 6478.04 & 0.069 & & Blend 2.7 Å FWHM \\
\hline 6482.05 & $\mathrm{~N}_{\text {II }}$ & 6482.05 & 0.025 & & \\
\hline 6496.9 & Ba II & 6496.37 & 0.015 & & Blend $3.3 \AA ̊$ FWHM \\
\hline 6500.04 & [Cr III $] ?$ & 6500.27 & 0.076 & \pm 0.004 & \\
\hline \multirow[t]{2}{*}{6516.53} & {$\left[\mathrm{~V}_{\mathrm{I}}\right]$} & 6516.40 & 0.043 & \pm 0.002 & \\
\hline & $?$ & 6521.68 & 0.006 & & \\
\hline 6527.10 & He II $(5-14)+$ & 6526.48 & 1.003 & \pm 0.001 & Blend 3.3 Å FWHM \\
\hline 6527.24 & {$[\mathrm{~N}$ II $]$} & & & & \\
\hline 6548.04 & {$[\mathrm{~N}$ II $]$} & 6548.09 & 173.1 & \pm 0.8 & \\
\hline 6560.2 & He II & 6559.98 & 9.463 & & Uncertain, on bright line wing \\
\hline \multirow[t]{2}{*}{6562.80} & $\mathrm{H} \alpha$ & 6562.78 & 292.5 & \pm 0.6 & \\
\hline & $?$ & 6575.05 & 0.088 & & \\
\hline \multirow[t]{3}{*}{6583.46} & {$[\mathrm{~N}$ II $]$} & 6583.46 & 504.6 & \pm 0.8 & \\
\hline & $?$ & 6611.00 & 0.011 & & \\
\hline & $?$ & 6624.72 & 0.013 & & \\
\hline 6655.52 & $\mathrm{C}_{\mathrm{I}}$ & 6655.71 & 0.045 & & \\
\hline 6666.66 & O II + & 6666.98 & 0.018 & & Blend 3.8 Å FWHM \\
\hline 6666.80 & {$[\mathrm{Ni} \mathrm{II}]+$} & & & & \\
\hline 6667.01 & {$[\mathrm{Fe} \mathrm{II}]$} & & & & \\
\hline 6678.15 & He I & 6678.20 & 4.328 & \pm 0.004 & \\
\hline 6683.20 & He II $(5-13)$ & 6683.20 & 0.586 & \pm 0.002 & \\
\hline \multirow[t]{2}{*}{6693.96} & {$[\mathrm{C} I]$} & 6693.95 & 0.112 & & \\
\hline & & & & & (continued) \\
\hline
\end{tabular}


Table 3. (Continued)

\begin{tabular}{|c|c|c|c|c|c|}
\hline$\lambda_{0}$ & Ion & $\lambda_{\mathrm{obs}}$ & $I(\lambda)$ & Error & Comment \\
\hline & ? & 6707.56 & 0.132 & & \\
\hline 6709.64 & {$[\mathrm{Li} I] ?$} & 6710.07 & 0.155 & \pm 0.006 & \\
\hline 6716.44 & {$[\mathrm{~S}$ II $]$} & 6716.43 & 12.75 & \pm 0.01 & \\
\hline 6730.81 & {$[\mathrm{~S}$ II $]$} & 6730.79 & 23.98 & \pm 0.01 & \\
\hline 6744.1 & $\mathrm{He}+$ & 6746.16 & 0.056 & & Blend $4.3 \AA ̊$ FWHM \\
\hline 6746.3 & CiV & & & & \\
\hline 6746.7 & CiV & & & & \\
\hline 6747.5 & CiV & & & & \\
\hline 6795.1 & {$[\mathrm{~K} \mathrm{IV}]$} & 6795.22 & 0.188 & \pm 0.002 & \\
\hline 6830 & $\begin{array}{l}\text { O vI } \\
\text { (Raman) }\end{array}$ & 6829.64 & 0.300 & & $\begin{array}{l}\text { Raman line with velocity structure: } \\
8.3 \AA \text { FWHM }\end{array}$ \\
\hline 6850.33 & [Mn II $]$ & 6850.19 & 0.084 & & \\
\hline \multirow[t]{2}{*}{6855.88} & He I & 6855.85 & 0.018 & \pm 0.002 & \\
\hline & $?$ & 6867.56 & 0.027 & & \\
\hline 6890.90 & He II (5-12) & 6891.00 & 0.661 & & \\
\hline 6927.85 & $\mathrm{~S}_{\text {II }}$ & 6928.23 & 0.046 & \pm 0.002 & \\
\hline 6984.08 & {$[\mathrm{Fe} \mathrm{II}]$} & 6984.36 & 0.022 & & \\
\hline 6989.45 & He I & 6989.43 & 0.011 & & \\
\hline 7005.4 & [Arv] & 7005.63 & 10.70 & \pm 0.01 & \\
\hline \multirow[t]{2}{*}{7046.88} & $\mathrm{Si}$ I & 7046.81 & 0.029 & & \\
\hline & $?$ & 7057.9 & 0.074 & & Blend $4.5 \AA$ FWHM \\
\hline 7065.19 & $\mathrm{He} \mathrm{I}$ & 7065.23 & 10.29 & \pm 0.01 & \\
\hline 7082.1 & Si I & 7082.06 & 0.009 & & \\
\hline \multirow[t]{2}{*}{7087} & $\begin{array}{l}\text { O vi } \\
\text { (Raman) }\end{array}$ & 7087.3 & 0.022 & & $\begin{array}{l}\text { Raman line with velocity structure: } \\
9 \AA \text { FWHM }\end{array}$ \\
\hline & $?$ & 7114.41 & 0.096 & & \\
\hline 7135.8 & [Ar III] & 7135.76 & 26.44 & \pm 0.05 & \\
\hline 7155.16 & {$[\mathrm{Fe} \mathrm{II}]$} & 7154.98 & 0.208 & \pm 0.003 & \\
\hline 7160.58 & He I & 7160.62 & 0.028 & \pm 0.005 & \\
\hline 7170.5 & [Ar IV] & 7170.61 & 1.559 & \pm 0.015 & \\
\hline 7177.52 & He II $(5-11)$ & 7177.60 & 0.882 & \pm 0.004 & \\
\hline 7237.40 & [Ar IV] & 7237.70 & 1.187 & \pm 0.006 & \\
\hline 7252.30 & Si I & 7252.49 & 0.016 & \pm 0.001 & \\
\hline 7255.8 & {$[\mathrm{Ni} \mathrm{II}]$} & 7255.98 & 0.016 & & \\
\hline 7262.7 & [Ar IV] & 7262.87 & 1.268 & \pm 0.008 & \\
\hline 7281.35 & He I & 7281.34 & 1.217 & \pm 0.01 & \\
\hline 7291.47 & [Ca II] & 7290.83 & 0.037 & & \\
\hline 7298.03 & He I & 7298.00 & 0.054 & \pm 0.001 & \\
\hline 7306.85 & $\mathrm{O}$ III+ & 7307.18 & 0.051 & \pm 0.004 & \\
\hline 7307.12 & O III & & & & \\
\hline 7318.92 & {$[\mathrm{OII}]+$} & 7320.06 & 10.51 & & \\
\hline 7319.99 & [O II] & & & & \\
\hline 7323.89 & {$[\mathrm{Ca}$ II $]$} & 7323.60 & 0.049 & & \\
\hline 7329.66 & {$[\mathrm{O} \mathrm{II}]+$} & 7330.37 & 9.182 & & \\
\hline 7330.73 & [O II] & & & & \\
\hline 7377.83 & [Ni II] & 7377.54 & 0.111 & \pm 0.005 & \\
\hline 7388.2 & {$[\mathrm{Fe} \mathrm{II}]$} & 7387.76 & 0.049 & & Possibly a blend \\
\hline 7411.61 & [Ni II] & 7411.32 & 0.010 & & \\
\hline \multirow[t]{2}{*}{7423.61} & $\mathrm{NI}_{\mathrm{I}}$ & 7423.40 & 0.008 & & \\
\hline & $?$ & 7439.90 & 0.015 & \pm 0.003 & \\
\hline 7442.30 & $\mathrm{~N}_{\mathrm{I}}$ & 7442.53 & 0.006 & & \\
\hline 7448.26 & $\mathrm{~N}_{\mathrm{I}}$ & 7447.91 & 0.005 & & \\
\hline 7452.54 & {$[\mathrm{Fe} \mathrm{II}]$} & 7452.29 & 0.073 & \pm 0.001 & \\
\hline 7468.31 & $\mathrm{~N}_{\mathrm{I}}$ & 7468.50 & 0.009 & \pm 0.001 & \\
\hline 7487.04 & {$[\mathrm{Fe}$ II $]+$} & 7487.19 & 0.007 & & Blend 2.6 $\mathrm{FWHM}$ \\
\hline 7486.7 & $\mathrm{C}_{\text {III }}$ & & & & \\
\hline 7499.85 & $\mathrm{He}_{\mathrm{I}}$ & 7499.82 & 0.054 & \pm 0.001 & \\
\hline 7530.0 & [Cl IV] & 7530.38 & 0.848 & \pm 0.001 & \\
\hline 7561.42 & [Mn II] & 7561.55 & 0.010 & \pm 0.001 & \\
\hline 7578.80 & Si I & 7578.80 & 0.046 & & \\
\hline 7581.5 & N IV & 7581.72 & 0.133 & \pm 0.02 & Blend $4.2 \AA$ FWHM \\
\hline \multirow[t]{2}{*}{7592.75} & He II $(5-10)+$ & 7592.76 & 1.487 & \pm 0.01 & \\
\hline & & & & & (continued) \\
\hline
\end{tabular}


Table 3. (Continued)

\begin{tabular}{|c|c|c|c|c|c|}
\hline$\lambda_{0}$ & Ion & $\lambda_{\text {obs }}$ & $I(\lambda)$ & Error & Comment \\
\hline 7592.0 & CIV & 7592.76 & 1.497 & \pm 0.03 & \\
\hline 7686.82 & N III & 7686.67 & 0.025 & & \\
\hline 7686.94 & {$[\mathrm{Fe} \mathrm{II}]$} & & & & \\
\hline 7703.0 & NiV+ & 7703.24 & 0.242 & & \\
\hline \multirow[t]{3}{*}{7703.4} & $\mathrm{~N}$ II & & & & \\
\hline & $?$ & 7712.67 & 0.038 & & \\
\hline & $?$ & 7716.78 & 0.090 & & \\
\hline \multirow[t]{3}{*}{7726.2} & CiV & 7726.11 & 0.028 & & \\
\hline & $?$ & 7731.02 & 0.027 & & \\
\hline & $?$ & 7737.88 & 0.035 & & \\
\hline 7751.1 & [Ar III] & 7751.10 & 7.384 & & \\
\hline 7816.13 & He I & 7816.15 & 0.077 & & \\
\hline \multirow{2}{*}{7837.76} & Ar II & 7837.72 & 0.011 & & \\
\hline & $?$ & 7857.56 & 0.0126 & \pm 0.003 & \\
\hline 7860.8 & CIV & 7861.37 & 0.019 & \pm 0.002 & \\
\hline 7875.99 & {$[\mathrm{P} I I]+$} & 7875.98 & 0.040 & \pm 0.001 & \\
\hline \multirow[t]{2}{*}{7876.6} & CIV & & & & \\
\hline & $?$ & 7883.45 & 0.039 & & \\
\hline 7924.2 & {$[\mathrm{Fe}$ III $]+$} & 7924.66 & 0.0311 & & \\
\hline \multirow[t]{3}{*}{7924.8} & [Fe III] & & & & \\
\hline & $?$ & 7935.38 & 0.036 & & \\
\hline & ? & 7968.65 & 0.017 & & \\
\hline 7999.4 & $\mathrm{He}+$ & 8000.10 & 0.0445 & & \\
\hline 8000.08 & {$[\mathrm{Cr} I \mathrm{I}]$} & & & & \\
\hline 8015.0 & $\mathrm{C}_{\mathrm{I}}$ & 8016.10 & 0.027 & & \\
\hline 8015.8 & He I(4-20) & & & & \\
\hline 8018.57 & $\mathrm{C}_{\mathrm{I}}$ & 8018.88 & 0.024 & & \\
\hline \multirow{2}{*}{8021.25} & $\mathrm{C}_{\mathrm{I}}$ & 8021.40 & 0.025 & & \\
\hline & $?$ & 8025.56 & 0.005 & & \\
\hline 8034.8 & He I(4-19) & 8035.52 & 0.006 & & \\
\hline 8039.77 & $\mathrm{C}_{\mathrm{I}}$ & 8039.50 & 0.056 & & \\
\hline 8046.3 & [Cl IV] & 8045.62 & 1.931 & \pm 0.002 & \\
\hline 8057.3 & He I(4-18) & 8057.61 & 0.014 & & \\
\hline 8064.8 & $\mathrm{~N}_{\text {II }}$ & 8064.78 & 0.081 & & \\
\hline 8083.8 & $\mathrm{C}_{\mathrm{I}}$ & 8084.00 & 0.013 & \pm 0.002 & \\
\hline 8116.49 & O II & 8116.32 & 0.015 & & \\
\hline \multirow[t]{5}{*}{8125.30} & {$[\mathrm{Cr} I \mathrm{II}]$} & 8125.39 & 0.032 & & \\
\hline & $?$ & 8137.36 & 0.0154 & & \\
\hline & $?$ & 8160.12 & 0.060 & & \\
\hline & $?$ & 8196.55 & 0.121 & \pm 0.008 & \\
\hline & $?$ & 8216.50 & 0.016 & & \\
\hline 8229.67 & [Cr II] & 8230.00 & 0.032 & \pm 0.013 & \\
\hline 8236.79 & He II (5-9) & 8236.75 & 2.152 & \pm 0.1 & \\
\hline 8267.94 & H I(P34) & 8267.93 & & & \\
\hline 8271.93 & H I(P33) & 8271.92 & & & \\
\hline 8276.31 & H I(P32) & 8276.41 & 0.094 & \pm 0.008 & \\
\hline 8281.12 & H I(P31) & 8281.33 & 0.134 & \pm 0.008 & \\
\hline 8286.43 & H I(P30) & 8286.42 & 0.122 & \pm 0.013 & \\
\hline 8292.31 & H I(P29) & 8292.18 & 0.119 & \pm 0.008 & \\
\hline \multirow[t]{2}{*}{8298.83} & H I(P28) & 8298.84 & 0.139 & \pm 0.007 & \\
\hline & $?$ & 8303.13 & 0.014 & & \\
\hline 8306.11 & H I(P27) & 8306.42 & 0.160 & \pm 0.008 & Blend $2.8 \AA \mathrm{FWHM}$ \\
\hline \multirow[t]{2}{*}{8314.26} & H I(P26) & 8314.20 & 0.151 & \pm 0.009 & \\
\hline & $?$ & 8320.17 & 0.032 & & \\
\hline \multirow[t]{2}{*}{8323.42} & H I (P25) & 8323.40 & 0.158 & \pm 0.006 & \\
\hline & $?$ & 8329.77 & 0.031 & \pm 0.006 & \\
\hline 8333.78 & $\mathrm{HI}(\mathrm{P} 24)$ & 8333.84 & 0.190 & \pm 0.01 & \\
\hline 8342.35 & He I & 8342.38 & 0.048 & \pm 0.008 & \\
\hline \multirow[t]{3}{*}{8345.55} & H I(P23) & 8345.53 & 0.176 & \pm 0.013 & \\
\hline & $?$ & 8348.55 & 0.013 & & \\
\hline & $?$ & 8355.45 & 0.011 & & \\
\hline 8359.00 & H I(P22) & 8359.06 & 0.226 & \pm 0.013 & \\
\hline 8361.73 & $\mathrm{He} \mathrm{I}_{\mathrm{I}}$ & 8361.73 & 0.161 & \pm 0.02 & \\
\hline
\end{tabular}


Table 3. (Continued)

\begin{tabular}{|c|c|c|c|c|c|}
\hline$\lambda_{0}$ & Ion & $\lambda_{\text {obs }}$ & $I(\lambda)$ & Error & Comment \\
\hline & $?$ & 8370.77 & 0.020 & \pm 0.004 & \\
\hline \multirow[t]{4}{*}{8374.47} & $\mathrm{HI}(\mathrm{P} 21)$ & 8374.51 & 0.220 & \pm 0.006 & \\
\hline & $?$ & 8379.29 & 0.025 & & \\
\hline & $?$ & 8386.57 & 0.072 & & \\
\hline & $?$ & 8388.13 & 0.030 & & \\
\hline 8392.40 & H I (P20) & 8392.40 & 0.254 & \pm 0.015 & \\
\hline \multirow[t]{2}{*}{8399} & He II & 8398.61 & 0.036 & \pm 0.008 & Blend $3.7 \AA \mathrm{FWHM}$ \\
\hline & $?$ & 8409.82 & 0.014 & & \\
\hline \multirow[t]{3}{*}{8413.32} & H I(P19) & 8413.33 & 0.271 & \pm 0.003 & \\
\hline & $?$ & 8421.81 & 0.030 & \pm 0.003 & \\
\hline & $?$ & 8424.61 & 0.010 & & \\
\hline 8434.0 & {$[\mathrm{Cl} \mathrm{III}]$} & 8433.87 & 0.092 & & \\
\hline 8437.95 & H I(P18) & 8437.95 & 0.313 & & \\
\hline \multirow[t]{5}{*}{8446.4} & O I & 8446.58 & 0.190 & & Possible blend \\
\hline & $?$ & 8451.16 & 0.020 & & \\
\hline & $?$ & 8453.73 & 0.013 & & \\
\hline & $?$ & 8459.16 & 0.017 & & \\
\hline & $?$ & 8463.80 & 0.029 & & \\
\hline \multirow[t]{2}{*}{8467.25} & H I(P17) & 8467.26 & 0.364 & \pm 0.003 & \\
\hline & $?$ & 8474.35 & 0.009 & & Blend $3.3 \AA \mathrm{FWHM}$ \\
\hline 8480.68 & $\mathrm{He} \mathrm{I}+$ & 8480.84 & 0.092 & \pm 0.003 & \\
\hline 8481.2 & [Cl III] & & & & \\
\hline 8486.2 & $\mathrm{He} \mathrm{I}$ & 8486.30 & 0.023 & \pm 0.003 & \\
\hline 8488.7 & $\mathrm{He}_{\mathrm{I}}$ & 8488.73 & 0.012 & & \\
\hline 8500.2 & [Cl III] & 8499.67 & 0.101 & & \\
\hline 8502.48 & HI $\mathrm{I}(\mathrm{P} 16)$ & 8502.35 & 0.458 & \pm 0.03 & \\
\hline 8519.3 & He II (6-31) & 8519.14 & 0.033 & \pm 0.003 & \\
\hline 8528.9 & $\mathrm{He}_{\mathrm{I}}$ & 8529.09 & 0.024 & \pm 0.003 & \\
\hline 8532.1 & $\mathrm{He}_{\mathrm{I}}$ & 8531.91 & 0.008 & & \\
\hline
\end{tabular}

between the incident $\operatorname{Ly} \beta$ photon and the outgoing, scattered photons. For this process to work we require a very high flux in the O vI doublet at 1032 and $1038 \AA$, in the same region of space where there is a high column density of neutral hydrogen. Normally these conditions are only encountered in symbiotic stars, and it is believed that this is the first time these lines have been detected in a planetary nebula.

Third, the recombination lines of $\mathrm{Si}$ (e.g. Si II $\lambda 3862.60 \AA$, $\lambda 5041.0 \AA$, and Si III $\lambda 3956.64 \AA$ are unusually strong. Taken along with the extraordinary strength of the $1.96 \mu \mathrm{m}$ [Si vI] and $2.486 \mu \mathrm{m}$ [Si VII] lines in the infrared (Ashley \& Hyland 1988), this is direct evidence that silicaceous dust is being destroyed in the inner nebula. The smaller grains that we see here then may have been produced by grain-grain collisions which have led to grain shattering.

Fourth, in addition to these recombination lines, there is a rich set of recombination lines of more abundant elements. A crude analysis of these to estimate the abundances of several ions is shown in Table 4. Though the estimates vary by a factor of two in some ions, they do not lead one to believe that the abundances derived from recombination lines are unusually high, unlike the case reported by Liu et al. (2000). Note that this observation also supports our assumption of a high temperature when calculating the continuum emission. The difference in Balmer jump and [O $\mathrm{III}]$ temperatures correlates with the
Table 4. NGC 6302 Recombination line ion abundances

Some of the weaker lines may be blends hence the large variation

\begin{tabular}{lllcl}
\hline Ion & Line $(\AA)$ & $\begin{array}{l}\text { Recombination } \\
\text { coefficient }\end{array}$ & Intensity & Abundance \\
\hline $\mathrm{H}^{+}$ & 4861 & $2.10 \mathrm{E}-14$ & 100.0 & 1.00 \\
$\mathrm{He}^{+}$ & 5876 & $3.11 \mathrm{E}-14$ & 20.4 & 0.16 \\
& 4471 & $8.93 \mathrm{E}-15$ & 5.43 & 0.11 \\
& 4922 & $2.62 \mathrm{E}-15$ & 1.56 & 0.13 \\
$\mathrm{He}^{+2}$ & 4686 & $2.36 \mathrm{E}-13$ & 67.5 & 0.058 \\
$\mathrm{C}^{+2}$ & 4267 & $1.77 \mathrm{E}-13$ & 0.080 & $8.3 \mathrm{E}-5$ \\
$\mathrm{C}^{+3}$ & 8197 & $2.34 \mathrm{E}-13$ & 0.121 & $1.9 \mathrm{E}-4$ \\
& 4187 & $9.66 \mathrm{E}-14$ & 0.141 & $2.6 \mathrm{E}-4$ \\
$\mathrm{C}^{+4}$ & 7726 & $6.17 \mathrm{E}-13$ & 0.028 & $1.5 \mathrm{E}-5$ \\
$\mathrm{~N}^{+2}$ & 5941.6 & $2.70 \mathrm{E}-14$ & 0.022 & $2.1 \mathrm{E}-4$ \\
& 4040.9 & $5.70 \mathrm{E}-14$ & 0.070 & $2.2 \mathrm{E}-4$ \\
& 4239.4 & $3.70 \mathrm{E}-14$ & 0.047 & $2.2 \mathrm{E}-4$ \\
& 5679.6 & $5.80 \mathrm{E}-14$ & 0.154 & $6.5 \mathrm{E}-4$ \\
$\mathrm{~N}^{+3}$ & 4379 & $3.95 \mathrm{E}-13$ & 0.270 & $1.3 \mathrm{E}-4$ \\
$\mathrm{~N}^{+4}$ & 7703 & $4.03 \mathrm{E}-13$ & 0.242 & $2.0 \mathrm{E}-4$ \\
& 7582 & $1.57 \mathrm{E}-13$ & 0.133 & $2.8 \mathrm{E}-4$ \\
$\mathrm{O}^{+2}$ & 4089.3 & $1.84 \mathrm{E}-14$ & 0.060 & $5.7 \mathrm{E}-4$ \\
& 4132.8 & $1.07 \mathrm{E}-14$ & 0.061 & $1.02 \mathrm{E}-3$ \\
& 4649.1 & $1.04 \mathrm{E}-13$ & 0.232 & $4.5 \mathrm{E}-4$ \\
& 4676.2 & $2.03 \mathrm{E}-14$ & 0.091 & $9.1 \mathrm{E}-4$ \\
$\mathrm{O}^{+3}$ & 5592 & $6.95 \mathrm{E}-15$ & 0.074 & $2.5 \mathrm{E}-3$ \\
$\mathrm{O}^{+4}$ & 7715 & $4.03 \mathrm{E}-13$ & 0.090 & $7.5 \mathrm{E}-5$ \\
\hline
\end{tabular}

${ }^{1}$ Measured at $15,000 \mathrm{~K}$. 
difference between the forbidden line and recombination line abundances (Liu et al. 2001), and with the measured abundances approximately the same, the temperatures should also be similar.

\section{Discussion and Conclusion}

A high signal-to-noise ratio, high resolution spectrum of the bright planetary nebula NGC 6302 was obtained with a wavelength range covering the visible spectrum, and its continuum has been used to provide the first detection of the central star of NGC 6302 and to determine the reddening function of the dust in the nebula.

As far as the authors know this is the first time the continuum of a planetary nebula has been measured to such accuracy over such a wide range, and the first time the intrinsic reddening curve of a nebula has been determined from the form of the nebular continuum. Certainly, the continuum distribution of planetary nebulae has been used before, but mainly to measure the electron temperature of the nebulae (Liu \& Danziger 1993).

The UV steepening of the reddening curve of NGC 6302 is taken to mean that there is a higher abundance of small dust grains in the nebula than is found in the interstellar medium. However, with only one example, it is not known whether this property is common to all planetary nebulae or just to those of Type I composition.

\section{Acknowledgements}

We wish to acknowledge the use of the Atomic Line List (http://www.pa.uky.edu/ peter/atomic/) in the identification of the emission lines made here.

M. Dopita wishes to thank the Visitor Program of the Space Telescope Science Institute, and of the Universit'e d'Aix-Marseille during his visit to LAS, during which the spectroscopic analysis described here was carried out. He would also like to acknowledge the support of the Australian National University and the Australian
Research Council (ARC) for his ARC Australian Federation Fellowship, and also the ARC Discovery project DP0208445.

\section{References}

Aller, L. H., Ross, J. E., O’Mara, B. J., \& Keyes, C. D. 1981, MNRAS, 197, 95

Ashley, M. C. B. 1988, PhD Thesis, The Australian National University

Ashley, M. C. B. 1990, PASA, 8, 360

Ashley, M. C. B., \& Hyland, A.R. 1988, ApJ, 331, 532

Bessell, M. S. 1999, PASP, 111, 1426

Brown, R. L., \& Mathews, W. G. 1970, ApJ, 160, 939

Dopita, M. A., \& Hua, C. T. 1997, ApJS, 108, 515

Dopita, M. A., \& Sutherland, R. S. 2002, Astrophysics of the Diffuse Universe (Berlin: Springer-Verlag), in press

Habing, H. J., Tignon, J., \& Tielens, A. G. G. M. 1994, A\&A, 286,523

Hua, C. T., Dopita, M. A., \& Martinis, J. 1997, A\&AS, 133, 361

Kaler, J. B. 1976, ApJS, 31, 517

Kemper, F., Jäger, C., Waters, L. B. F. M, Henning, Th., Molster, F. J., Barlow, M. J., Lim, T., \& de Koter, A. 2002, Nature, 415, 295

Kozasa, T., \& Sogawa, H. 1997, Ap\&SS, 251, 165

Lester, D. F., \& Dinerstein, H. L. 1984, ApJ, 281, L67

Liu, X., \& Danziger, J. 1993, MNRAS, 263, 256

Liu, X.-W., Luo, S. G., Barlow, M. J., Danziger, I. J., \& Storey, P. J. 2001, MNRAS, 327, 141

Liu, X.-W., Storey, P. J., Barlow, M. J., Danziger, I. J., Cohen, M., \& Bryce, M. 2000, MNRAS, 312, 583

Loup, C., Foreville, T., Omont, A., \& Paul, J. F. 1993, A\&AS, 99, 291

Milne, D. K., \& Aller, L. H. 1975, A\&A, 38, 183

Osterbrock, D. E. 1989, Astrophysics of Gaseous Nebulae and Active Galactic Nuclei (Mill Valley, CA: University Science Books)

Péquignot, D., Baluteau, J.-P., Morisset, C., \& Boisson, C. 1997, A\&A, 323, 217

Perek, L. 1971, BAICz, 22, 103

Pottasch, S. R. 1984, Planetary Nebulae - A Study of Late Stages of Stellar Evolution (Dordecht: Reidel)

Rodgers, A., Conroy, P., \& Bloxham, G. 1988, PASP, 100, 626

Rodriguez, L. F., et al. 1985, MNRAS, 215, 353

Schmid, H. M. 1989, A\&A, 211, 31

Sutherland, R. S., \& Dopita, M. A. 1993, ApJS, 88, 253

Waters, L. B. F. M., et al. 1996, ApJ, 315, L361

Whitford, A. E. 1958, AJ, 63, 201 